\title{
The Preliminary Results for Five-System Ultra-Rapid Precise Orbit Determination of the One-Step Method Based on the Double-Difference Observation Model
}

\author{
Fei Ye ${ }^{1,2,3}$, Yunbin Yuan ${ }^{1,2, *}$, Bingfeng Tan ${ }^{1,2} \oplus$, Zhiguo Deng ${ }^{4}$ and Jikun Ou ${ }^{1,2}$ \\ 1 Institute of Geodesy and Geophysics, CAS, 340 Xudong Street, Wuhan 430077, China; \\ feiye@whigg.ac.cn (F.Y.); bingfengtan@whigg.ac.cn (B.T.); ojk@asch.whigg.ac.cn (J.O.) \\ 2 State Key Laboratory of Geodesy and Earth's Dynamics, 340 Xudong Street, Wuhan 430077, China \\ 3 College of Earth and Planetary Sciences, University of Chinese Academy of Sciences, A19 Yuquan Road, \\ Beijing 100049, China \\ 4 Deutsches GeoForschungsZentrum, TELEGRAFENBERG 1, 14473 Potsdam, Germany; \\ deng@gfz-potsdam.de \\ * Correspondence: yybgps@whigg.ac.cn; Tel.: +86-027-68881072
}

Received: 7 November 2018; Accepted: 21 December 2018; Published: 29 December 2018

\begin{abstract}
The predicted parts of ultra-rapid orbits are important for (near) real-time Global Navigation Satellite System (GNSS) precise applications; and there is little research on GPS/GLONASS/BDS/Galileo/QZSS five-system ultra-rapid precise orbit determination; based on the one-step method and double-difference observation model. However; the successful development of a software platform for solving five-system ultra-rapid orbits is the basis of determining and analyzing these orbits. Besides this; the different observation models and processing strategies facilitate to validate the reliability of the various ultra-rapid orbits. In this contribution; this paper derives the double-difference observation model of five-system ultra-rapid precise orbit determination; based on a one-step method; and embeds this method and model into Bernese v5.2; thereby forming a new prototype software platform. For validation purposes; 31 days of real tracking data; collected from 130 globally-distributed International GNSS Service (IGS) multi-GNSS Experiment (MGEX) stations; are used to determine a five-system ultra-rapid precise orbit. The performance of the software platform is evaluated by analysis of the orbit discontinuities at day boundaries and by comparing the consistency with the MGEX orbits from the Deutsches GeoForschungsZentrum (GFZ); between the results of this new prototype software platform and the ultra-rapid orbit provided by the International GNSS Monitoring and Assessment System (iGMAS) analysis center (AC) at the Institute of Geodesy and Geophysics (IGG). The test results show that the average standard deviations of orbit discontinuities in the three-dimension direction are $0.022 ; 0.031$; 0.139; 0.064; 0.028; and 0.465 m for GPS; GLONASS; BDS Inclined Geosynchronous Orbit (IGSO); BDS Mid-Earth Orbit (MEO); Galileo; and QZSS satellites; respectively. In addition; the preliminary results of the new prototype software platform show that the consistency of this platform has been significantly improved compared to the software package of the IGGAC.
\end{abstract}

Keywords: multi-GNSS; ultra-rapid precise orbit determination; one-step method; double-difference observation model

\section{Introduction}

The launches of the first Galileo In-Orbit Validation Element (GIOVE) satellite in 2005 and the first experimental satellite of the Chinese regional BeiDou navigation satellite system (BDS-2) in 2007 marked the beginning of a new era in satellite navigation [1]. Currently, the navigation 
satellite systems that already provide position, navigation, and timing services include American GPS, Russian GLONASS, European Galileo, Chinese BDS, Japanese Quasi-Zenith Satellite System (QZSS), and so on. Montenbruck et al. have also analyzed the signal-in-space ranging errors of the broadcast ephemeris messages of these five navigation satellite systems [2]. By the end of January 2018, the GPS/GLONASS/BDS/Galileo/QZSS constellation was composed of 31/24/14/15/3 satellites, respectively, with operational capability. Each navigation satellite system also has its own future constellation construction plan. For users, there will be more satellites available in the future, and these satellites will also have better performance (e.g., in 2020, the Chinese global BeiDou navigation satellite system (BDS-3) will be composed of five geostationary earth orbit (GEO), three inclined geosynchronous orbit (IGSO), and twenty-seven medium earth orbit (MEO) satellites). Recently, BDS-3 has entered the intensive launch phase, and two BDS-3 satellites were launched on October 15, 2018. At the end of October 2018, there are 18 BDS-3 satellites being tested (http:/ / www.csno-tarc. $\mathrm{cn} /$ system/constellation). The construction and in-orbit operation of multiple navigation satellite systems can provide more reliable and accurate results for global navigation satellite system (GNSS) applications (e.g., atmospheric remote sensing [3-5], precise point positioning [6-8], precise relative positioning [9,10], and the calculation of Earth rotation parameters [11]). At the same time, the multiple constellations also bring great challenges to the data processing of multi-GNSS. In order to promote the scientific and engineering applications of multi-GNSS in high-precision fields, the International GNSS Service (IGS) initiated the multi-GNSS experiment (MGEX) in 2011 (ftp:/ /igs.org/pub/resource/ pubs/IGSM-GEXVF.pdf). Generally, seven MGEX analysis centers (ACs) provide special multi-GNSS precise orbit products to MGEX. These ACs are the Centre National d'Etudes Spatiales (CNES) and Collecte Localisation Satellites (CLS) in France; the Center for Orbit Determination in Europe (CODE) in Switzerland; the Deutsches GeoForschungsZentrum (GFZ), the Technische Universität München (TUM), and the European Space Agency (ESA) in Germany; Wuhan University (WU) in China, and the Japan Aerospace Exploration Agency (JAXA) in Japan. Among them, CODE, GFZ, and WU can provide five-system final precise orbit products, and ESA have only provided two-week final precise orbit products in the past.

Because the accuracy of satellite orbits directly affects the accuracy of GNSS user position, navigation, and timing applications, GNSS precise orbit determination (POD) technology has become one of the key technologies in some GNSS research institutes (e.g., MGEX ACs). The techniques for the precise orbit determination of GNSS satellites are mainly based on microwave GNSS observations and satellite laser ranging (SLR) data [12]. For these reasons, these institutes have independently developed or redeveloped corresponding GNSS POD software platforms. In general, the GNSS POD software platforms used by CNES/CLS, CODE, GFZ, TUM, ESA, WU, and JAXA are POD GINS [13], Bernese v5.3 [14], EPOS.P8 [15], Bernese v5.0 [16], NAPEOS 3.8 [17], PANDA [18], and MADOCA [19], respectively. In this paper, we mainly consider the processing method of microwave GNSS observations, and the process of GNSS POD; the error equations are established by using non-difference observations in all MGEX ACs, except for the double-difference observations used by Bernese v5.3. In addition, the solution strategies used by MGEX ACs in calculating multi-GNSS orbit parameters are not exactly the same: CNES/CLS, CODE [20], and GFZ use the one-step method strategy; TUM use the two-step method strategy [21]; and WU use the three-step method strategy. Studies have shown that more available satellites benefit the estimation of common parameters (such as station coordinates and tropospheric parameters) when using the one-step method. Theoretically, the one-step method strategy is a more rigorous solution, which is more conductive to multi-GNSS POD [22]. IGS MGEX also encourages MGEX ACs to use the one-step method. At present, IGS provides GPS/GLONASS two-system ultra-rapid orbits, and the International GNSS Monitoring and Assessment System (iGMAS) provides four-system (GPS/GLONASS/BDS/Galileo) ultra-rapid orbits (http:/ / www.igmas.org/). Besides, MGEX provides final precise orbits, and all MGEX ACs are testing their own ultra-rapid orbits. However, these ultra-rapid orbits are not fully released for GNSS users, and the published research and application of ultra-rapid orbits are mainly focused on a single or 
dual system [23,24]. Two other examples also show this problem: Kevin K. Choi et al. evaluated the prediction accuracy of IGS ultra-rapid orbit products [25]; and IGS ACs, such as CODE, introduced their solution strategies for IGS ultra-rapid orbit products $[26,27]$. Recently, based on the one-step method and non-difference observations, $\mathrm{Li}$ et al. proposed a method to solve the five-system ultra-rapid orbit problem [28]. There is relatively little data available at present regarding the introduction and research of a multi-GNSS (especially for five systems) ultra-rapid orbit based on the one-step method and the error equation of double-difference observations. On the other hand, a diversity of observation models and processing strategies will facilitate to validate the ultra-rapid orbits offered by various POD software platforms. Because the fact that the predicted part of the ultra-rapid orbits is important for a (near) real-time precise service, it is necessary to analyze these five-system ultra-rapid precise orbits provided by the one-step method and the error equation of double-difference observations. Developing a multi-GNSS POD software platform based on this method and error equation will be the premise of the corresponding analysis. However, Bernese v5.3 has not been released publicly, and Bernese v5.2 can only handle GPS/GLONASS/Galileo three-system data.

Therefore, this paper will derive the double-difference observation model of a multi-GNSS ultra-rapid POD based on the one-step method. A new prototype software platform for a five-system ultra-rapid POD will be developed on the basis of the Bernese v5.2 framework, and this model and method. The structure of this paper is as follows: First, the multi-GNSS observation model and the processing strategies of the software platform are introduced in the second section. Then, the preliminary results of this software platform are shown in the third section. Finally, the discussion and conclusions are given.

\section{Materials and Methods}

\subsection{The Multi-GNSS Observation Model of the New Prototype Software Platform}

In this paper, during the processing of the ultra-rapid POD solution, dual-frequency ionosphere-free (IF) combined observations were used to eliminate the first order of ionospheric delays. Hadas et al. showed that the impact of higher order ionosphere delays can reach several millimeters for the radial, along-track, and cross-track orbit components [29]. Considering that this paper only plans to get a preliminary result for five-system ultra-rapid orbits, the impact of higher order ionosphere delays was not considered. The observation equation of the IF combined observations can be linearized and expressed as follows:

$$
\begin{aligned}
& l_{r, I F}^{s}=\mu_{r}^{s} \cdot\left(\Phi\left(t, t_{0}\right)^{s} \cdot o_{o}^{s}-R_{r, \text { erp }} \cdot r_{r}\right)-\Delta t_{I F}^{s}+\Delta t_{r, I F}+\partial_{r}^{s} \cdot \delta_{\text {erp }} \\
& +\lambda_{I F}\left(b_{r, I F}-b_{I F}^{s}+N_{r, I F}^{s}\right)+m_{r, \text { trop }}^{s} \cdot \delta_{r, \text { trop }}+\varepsilon_{r, I F}^{s} \\
& p_{r, I F}^{s}=\mu_{r}^{s} \cdot\left(\Phi\left(t, t_{0}\right)^{s} \cdot o_{o}^{s}-R_{r, \text { erp }} \cdot r_{r}\right)-\Delta t_{I F}^{s}+\Delta t_{r, I F}+\partial_{r}^{s} \cdot \delta_{\text {erp }} \\
& +c\left(d_{r, I F}-d_{I F}^{s}\right)+m_{r, \text { trop }}^{s} \cdot \delta_{r, \text { trop }}+\omega_{r, I F}^{s}
\end{aligned}
$$

where

$$
\begin{gathered}
o_{o}^{s}=\left(a, e, i, \Omega, \omega, u_{0}, \mathrm{p}_{1 \sim 9}^{s}\right)^{T} \\
\delta_{\text {erp }}=\left(x_{0}, y_{0}, \theta_{0}\right)^{T}
\end{gathered}
$$

in addition, $l_{r, I F}^{s}$ and $p_{r, I F}^{s}$ denote the "observed minus computed" IF phase and pseudo-range observables from satellite $s$ to receiver $r$, respectively; $\mu_{r}^{s}$ represents the unit vector in the direction from receiver $r$ to satellite $s$; and $\Phi\left(t, t_{0}\right)^{s}$ is the state transition matrix from the initial epoch $t_{0}$ to current epoch $t . o_{o}^{s}$ denotes the initial orbit state vector of satellite $s$, including the semimajor axis of the orbit $a$, the eccentricity of the orbit $e$, the inclination of the orbital plane with respect to the equatorial plane $i$, the right ascension of the ascending node $\Omega$, the argument of perigee $\omega$, the argument of latitude $u_{0}$, and the solar radiation pressure (SRP) parameters of the empirical CODE orbit model 
(ECOM) developed by the Astronomical Institute, University of Bern $\left(\mathrm{p}_{1 \sim 9}^{s}\right)[30,31] . R_{r, \operatorname{erp}}$ denotes the satellite coordinates rotation matrix from the Earth-fixed frame to the inertial frame, according to the Earth rotation parameters (ERP); $r_{r}$ is the receiver position increments relative to the a priori position; $\Delta t_{I F}^{s}$ is the IF combined clock bias of satellite $s ; \Delta t_{r, I F}$ is the IF combined clock bias of receiver $r ; \partial_{r}^{s}$ is the partial derivative of the IF combined observation to ERP; $\delta_{\text {erp }}$ is the ERP, including polar motion $\left(x_{0}, y_{0}\right)$ and length of day change $\theta_{0} ; c$ is the speed of light in vacuo; $\lambda_{I F}$ is the wave-length of the IF combination; $b_{r, I F}$ and $b_{I F}^{s}$ are the receiver $r$ and satellite $s$ phase delays of IF combination, respectively; $N_{r, I F}^{s}$ is the ambiguity of the IF combination; $d_{r, I F}$ and $d_{I F}^{s}$ are the receiver $r$ and satellite $s$ code biases of the IF combination; $m_{r, \text { trop }}^{S}$ is a related mapping function with respect to the zenith tropospheric wet delays $\delta_{r, \text { trop }}$; and $\varepsilon_{r, I F}^{s}$ and $\omega_{r, I F}^{s}$ are the sum of measurement noise and multipath effects for the IF combined phase and pseudo-range observations, respectively.

In the same navigation satellite system, the observation equation of the linearized double-difference IF combination observation is as follows:

$$
\begin{aligned}
& \Delta \nabla l_{r 1 r 2, I F}^{s 1 s 2}=\left(\Delta \mu_{r 1 r 2}^{s 1} \cdot \Phi\left(t, t_{0}\right)^{s 1} \cdot o_{o}^{s 1}-\Delta \mu_{r 1 r 2}^{s 2} \cdot \Phi\left(t, t_{0}\right)^{s 2} \cdot o_{o}^{s 2}\right) \\
& +\lambda_{I F} \cdot \Delta \nabla N_{r 1 r 2, I F}^{s 1 s 2}+\Delta \nabla \partial_{r 1 r 2}^{s 1 s 2} \cdot \delta_{e r p} \\
& -\left(\Delta \mu_{r 1}^{s 1 s 2} \cdot R_{r 1, e r p} \cdot r_{r 1}-\Delta \mu_{r 2}^{s 1 s 2} \cdot R_{r 2, e r p} \cdot r_{r 2}\right) \\
& +\left(\Delta m_{r 1, t r o p}^{s 1 s 2} \cdot \delta_{r 1, t r o p}-\Delta m_{r 2, t r o p}^{s 1 s 2} \cdot \delta_{r 2, t r o p}\right)+\Delta \nabla \varepsilon_{r 1 r 2, I F}^{s 1 s 2} \\
& \Delta \nabla p_{r 1 r 2, I F}^{s 1 s 2}=\left(\Delta \mu_{r 1 r 2}^{s 1} \cdot \Phi\left(t, t_{0}\right)^{s 1} \cdot o_{o}^{s 1}-\Delta \mu_{r 1 r 2}^{s 2} \cdot \Phi\left(t, t_{0}\right)^{s 2} \cdot o_{o}^{s 2}\right) \\
& +\Delta \nabla \partial_{r 1 r 2}^{s 1 s 2} \cdot \delta_{\text {erp }} \\
& -\left(\Delta \mu_{r 1}^{s 1 s 2} \cdot R_{r 1, \text { erp }} \cdot r_{r 1}-\Delta \mu_{r 2}^{s 1 s 2} \cdot R_{r 2, \text { erp }} \cdot r_{r 2}\right) \\
& +\left(\Delta m_{r 1, t r o p}^{s 1 s 2} \cdot \delta_{r 1, t r o p}-\Delta m_{r 2, t r o p}^{s 1 s 2} \cdot \delta_{r 2, t r o p}\right)+\Delta \nabla \omega_{r 1 r 2, I F}^{s 1 s 2}
\end{aligned}
$$

where $\Delta \nabla l_{r 1 r 2, I F}^{s 1 s 2}$ is the double-difference IF combined phase of $l_{r, I F}^{s}$ between receivers $(r 1, r 2)$ and satellites $(s 1, s 2)$, and $\Delta \nabla p_{r 1 r 2, I F}^{s 1 s 2}$ has an analogous meaning; $\Delta \mu_{r 1}^{s 1 s 2}$ is the computed vector $\mu_{r 1}^{s 1}$ minus $\mu_{r 1}^{s 2}$, and $\Delta \mu_{r 2}^{s 1 s 2}$ has an analogous meaning; $\Delta \nabla N_{r 1 r 2, I F}^{s 1 s 2}$ is the double-difference IF combined ambiguity; $\Delta \nabla \partial_{r 1 r 2}^{s 1 s 2}$ is the double-difference partial derivative of $\partial_{r}^{s} ; \Delta m_{r 1, t r o p}^{s 1 s 2}$ is the computed mapping function given by $\Delta m_{r 1, \text { trop }}^{s 1}$ minus $\Delta m_{r 1, t r o p^{\prime}}^{s 2}$ and $\Delta m_{r 2, \text { trop }}^{s 1 s 2}$ has an analogous meaning; $\Delta \nabla \varepsilon_{r 1 r 2, I F}^{s 1 s 2}$ is the double-difference value of $\varepsilon_{r, I F}^{s}$ between receivers $(r 1, r 2)$ and satellites $(s 1, s 2)$, and $\Delta \nabla \omega_{r 1 r 2, I F}^{s 1 s 2}$ has an analogous meaning.

Based on the linearized double-difference IF combined observation equation, the five system (GPS/GLONASS/BDS/Galileo/QZSS) ultra-rapid POD observation model using the one-step method is obtained as follows:

$$
\begin{aligned}
& \Delta \nabla l_{r 1 r 2, I F}^{S 1 S 2}=\left(\Delta \mu_{r 1 r 2}^{S 1} \cdot \Phi\left(t, t_{0}\right)^{S 1} \cdot o_{o}^{S 1}-\Delta \mu_{r 1 r 2}^{S 2} \cdot \Phi\left(t, t_{0}\right)^{S 2} \cdot o_{o}^{S 2}\right) \\
& +\lambda_{I F} \cdot \Delta \nabla N_{r 1 r 2, I F}^{S 1 S 2}+\Delta \nabla \partial_{r 1 r 2}^{S 1 S 2} \cdot \delta_{e r p} \\
& -\left(\Delta \mu_{r 1}^{S 1 S 2} \cdot R_{r 1, \text { erp }} \cdot r_{r 1}-\Delta \mu_{r 2}^{S 1 S 2} \cdot R_{r 2, \text { erp }} \cdot r_{r 2}\right) \\
& +\left(\Delta m_{r 1, \text { trop }}^{S 1 S 2} \cdot \delta_{r 1, \text { trop }}-\Delta m_{r 2, \text { trop }}^{S 1 S 2} \cdot \delta_{r 2, \text { trop }}\right)+\Delta \nabla \varepsilon_{r 1 r 2, I F}^{S 1 S 2}
\end{aligned}
$$




$$
\begin{aligned}
& \Delta \nabla p_{r 1 r 2, I F}^{S 1 S 2}=\left(\Delta \mu_{r 1 r 2}^{S 1} \cdot \Phi\left(t, t_{0}\right)^{S 1} \cdot o_{o}^{S 1}-\Delta \mu_{r 1 r 2}^{S 2} \cdot \Phi\left(t, t_{0}\right)^{S 2} \cdot o_{o}^{S 2}\right) \\
& +\Delta \nabla \partial_{r 1 r 2}^{S 1 S 2} \cdot \delta_{\text {erp }} \\
& -\left(\Delta \mu_{r 1}^{S 1 S 2} \cdot R_{r 1, \text { erp }} \cdot r_{r 1}-\Delta \mu_{r 2}^{S 1 S 2} \cdot R_{r 2, \text { erp }} \cdot r_{r 2}\right) \\
& +\left(\Delta m_{r 1, \text { trop }}^{S 1 S 2} \cdot \delta_{r 1, \text { trop }}-\Delta m_{r 2, \text { trop }}^{S 1 S 2} \cdot \delta_{r 2, \text { trop }}\right)+\Delta \nabla \omega_{r 1 r 2, I F}^{S 1 S 2}
\end{aligned}
$$

where

$$
S=\left(G \text { or } R_{k} \text { or } C \text { or } E \text { or } J\right),
$$

besides, $G, R_{k}, C, E$, and $J$ refer to GPS, GLONASS, BDS, Galileo, and QZSS, respectively; and $k$ is the frequency factor in the frequency division multiple access (FDMA) mode.

Thus, in the five-system ultra-rapid POD solution, the unknown parameters, $X_{\text {pod, }}$, which need to be estimated include the initial orbit state vector $o_{o}^{s}$, the receiver position increments $r_{r}$, the double-difference IF combined ambiguity $\Delta \nabla N_{r 1 r 2, I F}^{s 1 s 2}$, the ERP $\delta_{e r p}$, and the zenith tropospheric wet delays $\delta_{r \text {,trop }}$, which are summarized in the following vector:

$$
X_{\text {pod }}=\left(o_{o}^{S 1} \ldots o_{o}^{S m}, r_{r}, \Delta \nabla N_{r 1 r 2, I F}^{S 1 S 2} \ldots \Delta \nabla N_{r 1 r 2, I F}^{S m S n}, \delta_{\text {erp }}, \delta_{r, \text { trop }}\right)
$$

In addition, in the data processing of Multi-GNSS observations in this paper, elevation-dependent weighting was adopted, and the weight function $w(z)$ is defined as follows [32]:

$$
w(z)=\left\{\begin{array}{r}
10000 \times \cos ^{2}(z) \text { forphase } \\
\cos ^{2}(z) \text { forcode }
\end{array}\right.
$$

where $z$ is the zenith angle of the satellite.

The above models are the important basis of the new prototype software platform for the five-system ultra-rapid POD. The following shows the processing strategies of the new prototype software platform.

\subsection{The Processing Strategies}

The new prototype software platform was developed on the basis of the Bernese v5.2 framework, and the above model and method, so the platform should be developed first to be able to simultaneously handle both five satellite systems and GNSS measurements stored in version 3 of the receiver independent exchange data format (RINEX) [33].

\subsubsection{Coordinate and Time Systems of the New Prototype Software Platform}

A unified coordinate system and time system are needed before five-system ultra-rapid POD. For the coordinate system, GPS, GLONASS, BDS, Galileo, and QZSS use the WGS84, PZ-90, CGCS2000, GTRF, and GRS80 ellipsoid systems [34-38], respectively. These coordinate systems are defined to approach the International Terrestrial Reference System (ITRS). According to Section 2.1, the double-difference observation model was used in our software platform, and so the differences between WGS84 and other coordinates can be ignored, except PZ-90 [39]. The transformation between WGS84 and PZ-90 can be realized by the Helmert seven-parameter model, and the transformation model is shown below: 


$$
\left(\begin{array}{c}
X_{G P S} \\
Y_{G P S} \\
Z_{G P S}
\end{array}\right)=\left(\begin{array}{c}
\Delta X \\
\Delta Y \\
\Delta Z
\end{array}\right)+(1+\alpha)\left(\begin{array}{ccc}
1 & \Delta \omega & -\Delta \varphi \\
-\Delta \omega & 1 & \Delta \varepsilon \\
\Delta \varphi & -\Delta \varepsilon & 1
\end{array}\right)\left(\begin{array}{c}
X_{G L O} \\
Y_{G L O} \\
Z_{G L O}
\end{array}\right)
$$

where $\left(\begin{array}{llll}X_{G P S} & Y_{G P S} & Z_{G P S}\end{array}\right)^{T}$ and $\left(\begin{array}{lll}X_{G L O} & Y_{G L O} & Z_{G L O}\end{array}\right)^{T}$ are the coordinates in the WGS84 and PZ-90 systems, respectively. Furthermore, $\left(\begin{array}{ccccccc}\Delta X & \Delta Y & \Delta Z & \alpha & \Delta \omega & \Delta \varphi & \Delta \varepsilon\end{array}\right)$ are the seven transformation parameters (ftp:/ / ftp.aiub.unibe.ch/BSWUSER52/GEN/DATUM).

For the time system, GPS, GLONASS, BDS, Galileo, and QZSS use the GPST, GLNT, BDT, GST, and QZSST systems, respectively. These time systems conform to UTC (USNO), UTC (SU), UTC (BSNC), UTC (PTB), and UTC (NICT), respectively. Their transformation model is shown below [34-39]:

$$
\left\{\begin{array}{l}
G P S T=G L N T-3 h+\Delta t_{L S}+\delta_{G P S T-G L N T} \\
G P S T=B D T+1356 \text { weeks }+14 s+\delta_{G P S T-B D T} \\
G P S T=G S T+\delta_{G P S T-G S T} \\
G P S T=Q Z S S T+\delta_{G P S T-Q Z S S T}
\end{array},\right.
$$

where $\Delta t_{L S}$ is the leap second of GLNT. $\delta_{G P S T-G L N T}, \delta_{G P S T-B D T}, \delta_{G P S T-G S T}$, and $\delta_{G P S T-Q Z S S T}$ are the micro-deviations between GPST and the GLNT, BDT, GST, and QZSST systems. In our software platform, these micro-deviations are ignored.

\subsubsection{Partial Available Strategies and the Flowchart of the New Prototype Software Platform}

There is research that has showed that the change of satellite orbit model can remarkably change the results of Galileo satellite POD [40], and Montenbruck et al. summarized the five-system satellite attitude models [41]. In this paper, the yaw-steering is assumed for all satellites, which is not yet correct for BDS and QZSS satellites. Besides, the ECOM 5-parameter model will be used for all satellites in the next section, but the model was not designed for Galileo, BDS, and QZSS satellites. The quality of the ultra-rapid orbits mostly depends on the satellite attitude models and the SRP model; therefore, the state of the new prototype software platform can be considered as preliminary.

Furthermore, during the processing of the five-system ultra-rapid POD in our new prototype software platform, the length of the arc and the setting of the stochastic pulses referred to the method proposed by Simon Lutz et al. [27]. The 06 (UTC), 12 (UTC), 18 (UTC), and 24 (UTC) ultra-rapid orbits used 54-h, 60-h, 66-h, and 72-h observations, respectively. Besides this, 3-5 sets of stochastic pulses were used in each arc. The cut-off angle was set to 3 degrees, and the data sampling rate was $180 \mathrm{~s}$. The available partial processing strategies are shown in Table 1, and Table 2 summarizes the observation types of each satellite navigation system selected from the observation files. In our software platform, the five-system observation and navigation files were processed simultaneously in response to MGEX's call for the joint processing of multi-GNSS, which is also needed for the five-system ultra-rapid POD using the one-step method. In addition, the flowchart of the new prototype software platform is shown in Figure 1. 
Table 1. The partial strategies of the new prototype software platform. IF: Ionosphere-free.

\begin{tabular}{cc}
\hline Items & Description \\
\hline Processing scheme & IF double-difference network processing \\
Solar radiation & ECOM 5-parameter model \\
Sampling interval & $180 \mathrm{~s}$ \\
Cut-off angle & 3 degrees \\
Tropospheric delay & GPT model, GMF mapping function, two-hourly ZTDs [42,43] \\
A priori ERP & IERS Bulletin A and continuous piecewise linear function [44] \\
Attitude & Yaw-steering always assumed for all sat \\
Ambiguity & Real constant value for each ambiguity arc \\
PCO/PCV(Sat) & GPS, GLONASS: PCO and PCV from IGS; Galileo: PCO and PCV from ESA; \\
PCO/PCV(Rec.) & BeiDou, QZSS: PCO from IGS MGEX \\
Update frequency & GPS, GLONASS: IGS PCO and PCV; new GNSS: adopted from GPS L1 and L2 \\
A priori orbits & $6 \mathrm{~h}$ \\
A priori coordinates & Broadcast ephemeris \\
Earth gravity & EGM2008 12 $\times 12$ [45] \\
Solid earth tide and pole & IERS2010 [46] \\
tide & FES2004 [47] \\
Ocean tide & IAU2000 [48] \\
Nutation model & IERS2010 [46] \\
N-body gravitation & Sun, moon \\
Relativity effect & and other planets (DE405) \\
\hline
\end{tabular}

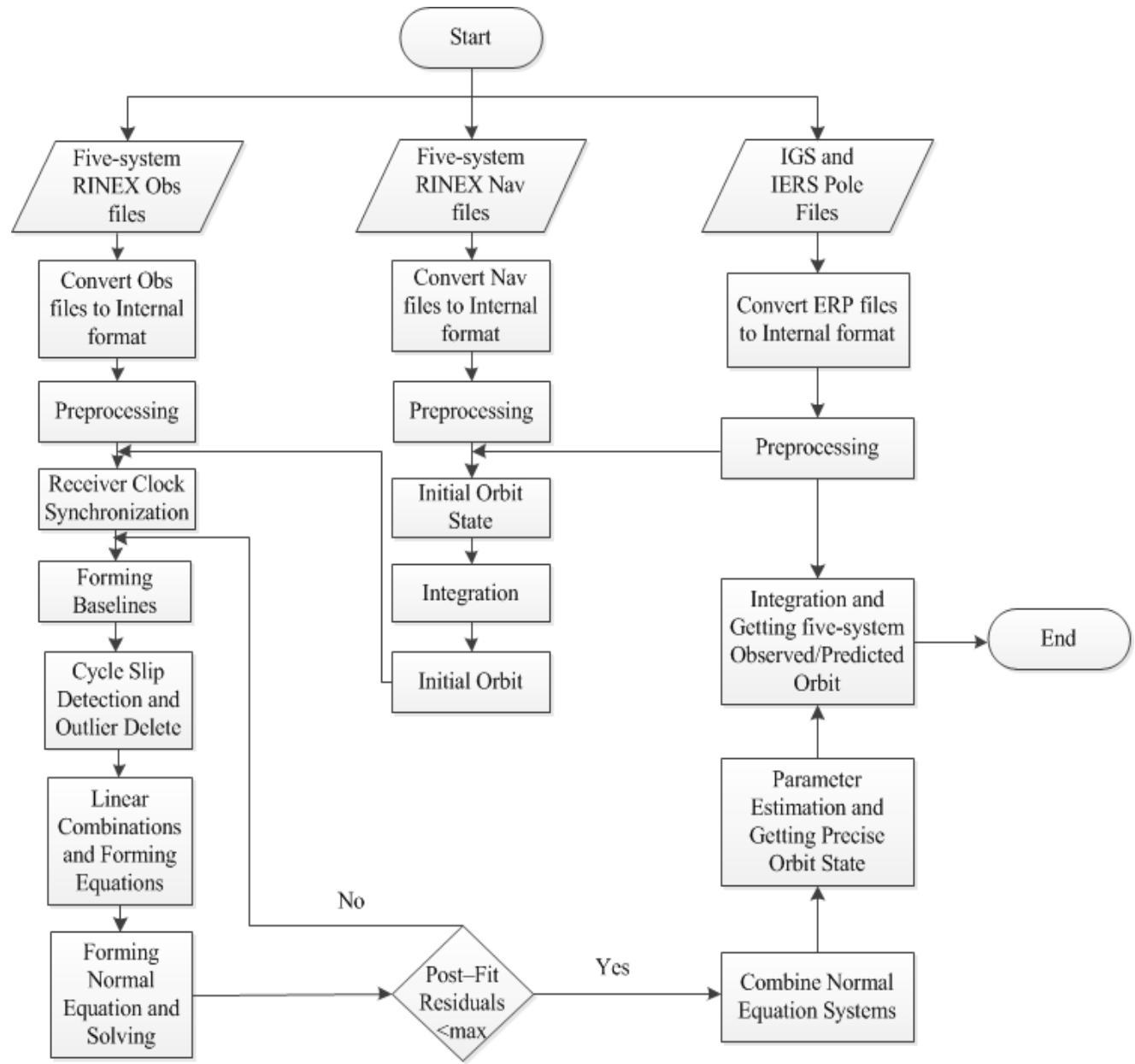

Figure 1. The flowchart of the new prototype software platform. Obs: observation; Nav: navigation. 
Table 2. The observation types selected by the new prototype software platform. Sys: System; G: GPS; $R$ : GLONASS ( $k$ : the frequency factor); C: BDS; E: Galileo; J: QZSS.

\begin{tabular}{|c|c|c|c|c|}
\hline \multirow{2}{*}{ Sys } & \multicolumn{2}{|c|}{ Frequency } & \multirow{2}{*}{\multicolumn{2}{|c|}{$\begin{array}{c}\text { Signal } \\
\text { Phase/Code }\end{array}$}} \\
\hline & Band & $\mathrm{MHz}$ & & \\
\hline \multirow{4}{*}{ G } & L1 & 1575.42 & L1C/C1C & $\mathrm{L} 1 \mathrm{~W} / \mathrm{C} 1 \mathrm{~W}$ \\
\hline & & & $\mathrm{L} 2 \mathrm{~W} / \mathrm{C} 2 \mathrm{~W}$ & L2X/C2X \\
\hline & L2 & 1227.60 & $\mathrm{~L} 2 \mathrm{~S} / \mathrm{C} 2 \mathrm{~S}$ & $\mathrm{~L} 2 \mathrm{~L} / \mathrm{C} 2 \mathrm{~L}$ \\
\hline & & & $\mathrm{L} 2 \mathrm{C} / \mathrm{C} 2 \mathrm{C}$ & $\mathrm{L} 2 \mathrm{D} / \mathrm{C} 2 \mathrm{D}$ \\
\hline \multirow{4}{*}{$R_{k}$} & $C 1$ & 1598.0625 & \multirow{2}{*}{\multicolumn{2}{|c|}{$\begin{array}{l}\text { L1C/C1C } \\
\text { L1P/C1P }\end{array}$}} \\
\hline & G1 & -1608.75 & & \\
\hline & & 1242.9375 & \multicolumn{2}{|c|}{$\mathrm{L} 2 \mathrm{P} / \mathrm{C} 2 \mathrm{P}$} \\
\hline & G2 & -1251.25 & \multicolumn{2}{|c|}{$\mathrm{L} 2 \mathrm{C} / \mathrm{C} 2 \mathrm{C}$} \\
\hline \multirow{2}{*}{ E } & E1 & 1575.42 & L1X/C1X & $\mathrm{L} 1 \mathrm{C} / \mathrm{C} 1 \mathrm{C}$ \\
\hline & E5a & 1176.45 & L5X/C5X & $\mathrm{L} 5 \mathrm{Q} / \mathrm{C} 5 \mathrm{Q}$ \\
\hline \multirow{3}{*}{ C } & & & L1I/C1I & L2I/C2I \\
\hline & B1 & 1561.098 & \multicolumn{2}{|c|}{$\mathrm{L} 2 \mathrm{X} / \mathrm{C} 2 \mathrm{X}$} \\
\hline & B2 & 1207.14 & L7I/C7I & L7X/C7X \\
\hline \multirow{3}{*}{$\mathrm{J}$} & L1 & 1575.42 & $\mathrm{~L} 1 \mathrm{C} / \mathrm{C} 1 \mathrm{C}$ & L1X/C1X \\
\hline & & & $\mathrm{L} 2 \mathrm{X} / \mathrm{C} 2 \mathrm{X}$ & $\mathrm{L} 2 \mathrm{~L} / \mathrm{C} 2 \mathrm{~L}$ \\
\hline & L2 & 1227.60 & \multicolumn{2}{|c|}{$\mathrm{L} 2 \mathrm{~S} / \mathrm{C} 2 \mathrm{~S}$} \\
\hline
\end{tabular}

The above section introduces the models, methods, and processing strategies used in the new prototype software platform. Although the double-difference IF combined observation equations are constructed in the same navigation satellite systems, all satellites and these equations are solved together in a least square estimator.

\section{Preliminary Results}

In order to test the basic performance of the new prototype software platform for the five-system ultra-rapid POD, one month's data collected from 130 globally-distributed IGS MGEX stations were used to determine and analyze the ultra-rapid orbit. Figure 2 shows the distribution of the selected tracking stations (the triangles show stations that can observe the four systems (GPS/GLONASS/BDS/Galileo), and the circles show stations that can observe the QZSS). Figure 2 shows that there are 130 stations which can observe four systems. Among them, 67 stations can observe all five systems. Figure 2 also shows that the tracking stations of QZSS have regional distribution. To facilitate the comparison with the MGEX orbit products, we unified the coordinate system to WGS84 and we unified the time system to GPST.

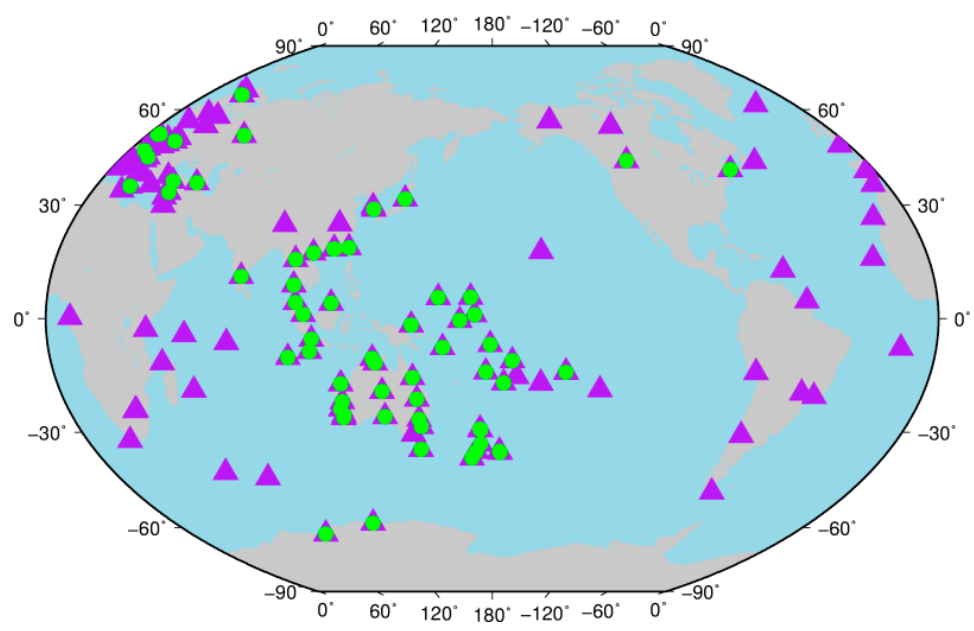

Figure 2. Distribution of tracking stations used for ultra-rapid precise orbit determination (triangles: GPS/GLONASS/BDS/Galileo; circles: QZSS). 
The test period was from 1 January 2018 to 31 January 2018. In this paper, the ultra-rapid orbits of MEO and IGSO satellites were tested. The methods to assess the predicted parts of multi-GNSS ultra-rapid orbits are mainly the analysis of the orbit discontinuities at day boundaries, comparison with IGS/MGEX orbit, and SLR validation, etc. [28,49,50]. In this section, we used the first two validation methods, and the assessment steps were carried out as follows:

1. Five-system ultra-rapid orbits were estimated, and the time latency for estimated ultra-rapid orbits is shown in Figure 3;

2. The six-hour predicted part of each arc were compared to the final MGEX orbit products of GFZ (the accuracy codes are 0 for all satellites in gbm19861.sp3), and the root mean square (RMS) of the position deviation in the radial, along-track, and cross-track directions orbit components was calculated. Figures A1-A5 of Appendix A represent the differences between the predicted orbits of five-system ultra-rapid orbits and the orbits of GFZ for GPS, GLONASS, BDS, Galileo, and QZSS satellites. Figures 4-7 represent the root mean square (RMS) of these satellites;

3. The analysis of the orbit discontinuities at day boundaries. Figures A6-A10 of Appendix A represent the residuals of the fitting procedure for GPS, GLONASS, BDS, Galileo, and QZSS satellites in the radial, along-track, and cross-track directions orbit components. Figures 8-11 represent the standard deviations (SD) of these satellites.

4. The Institute of Geodesy and Geophysics (IGG), as one of the iGMAS ACs, has provided ultra-rapid orbits estimated by the two-step method [51]; therefore, the six-hour predicted part of each arc for these orbits (named IGGAC in this paper) were compared to the final MGEX orbits of GFZ in the radial, along-track, and cross-track directions orbit components. In this test period, the available ultra-rapid orbits of IGGAC included satellites of GPS and GLONASS from 1 January 2018 to 31 January 2018, and of Galileo from 14 January 2018 to 31 January 2018. Figures A11-A13 of Appendix A represent the differences between the predicted orbits of IGGAC and the orbits of GFZ for GPS, GLONASS, and Galileo satellites. Figures 12-15 represent the root mean square (RMS) of these satellites. Table A1 of Appendix A shows the differences between the results of our new prototype software platform and IGGAC in consistency with the final MGEX orbit products of GFZ.

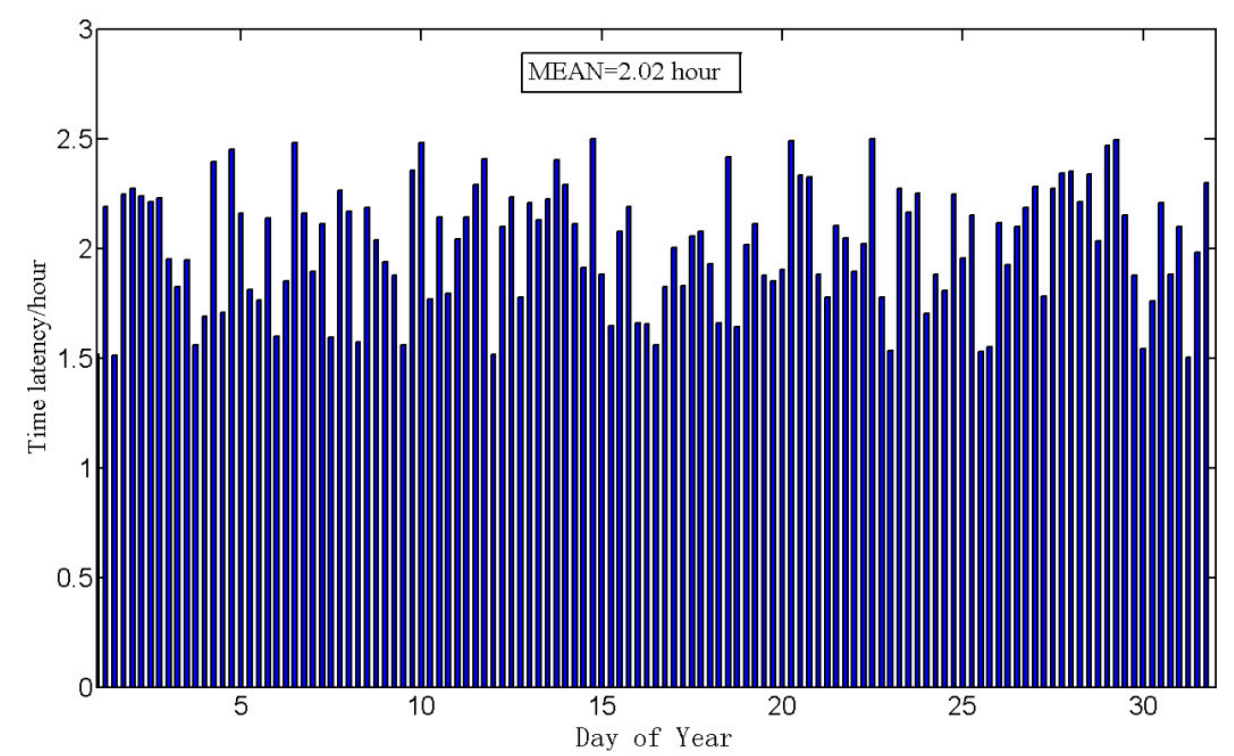

Figure 3. The time consumption for calculation (CPU 4.2GHz). 

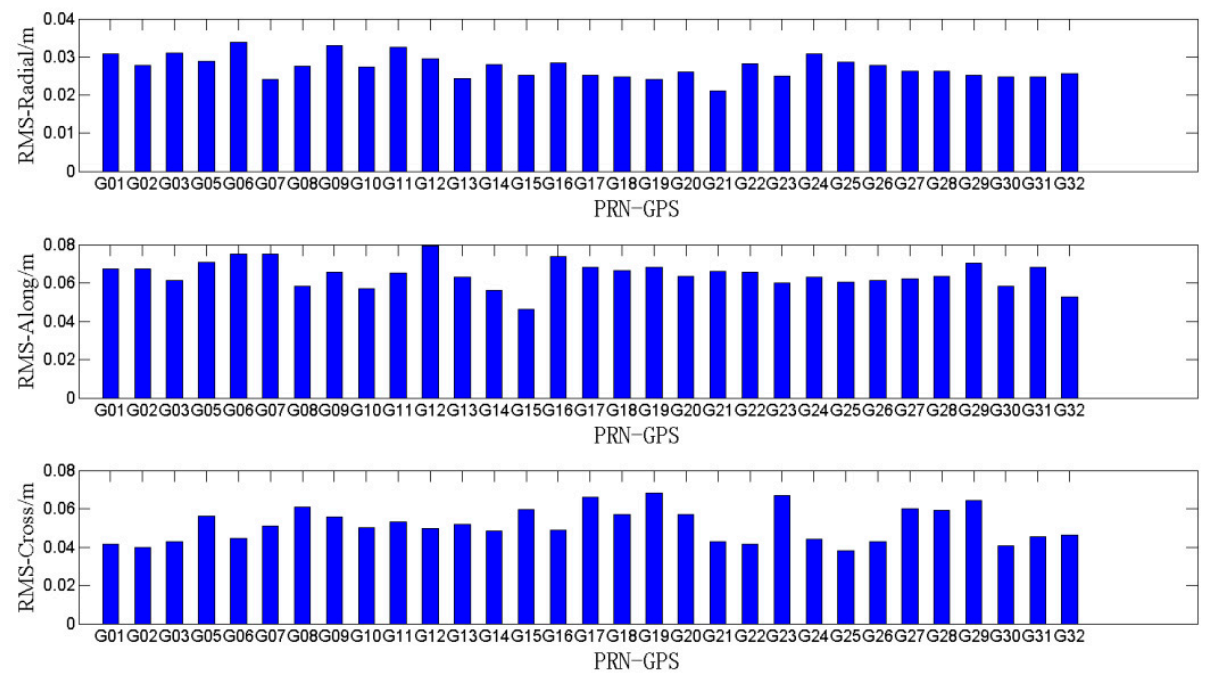

Figure 4. The root mean square (RMS) between the six-hour predicted orbits of the five-system ultra-rapid orbits and the orbits of GeoForschungsZentrum (GFZ) for GPS.

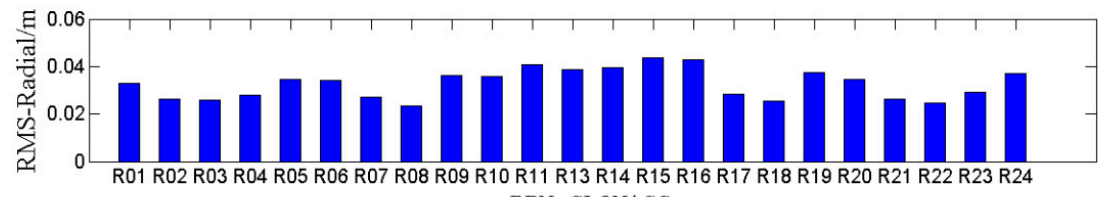

PRN-GLONASS

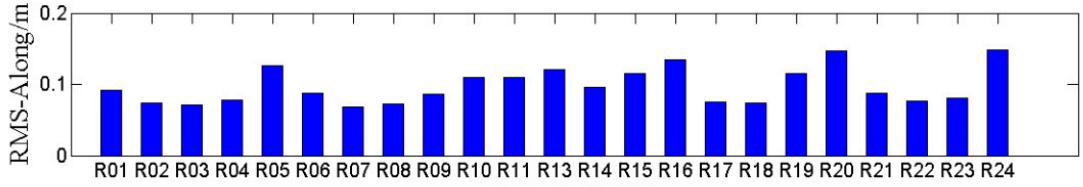

PRN-GLONASS

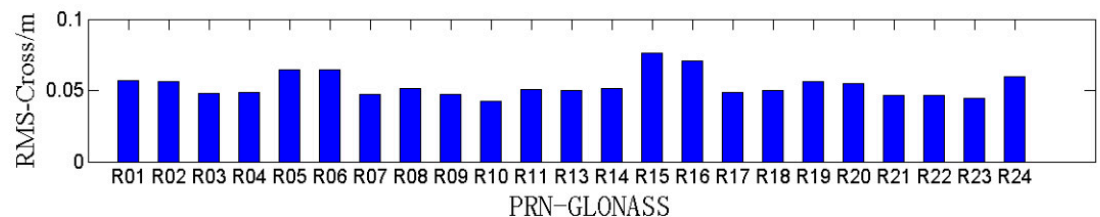

Figure 5. The RMS between the six-hour predicted orbits of the five-system ultra-rapid orbits and the orbits of GFZ for GLONASS.

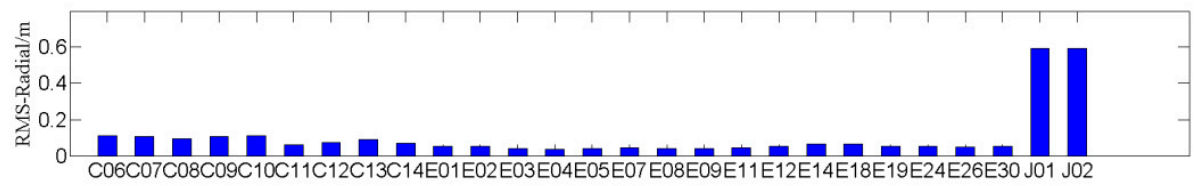

PRN
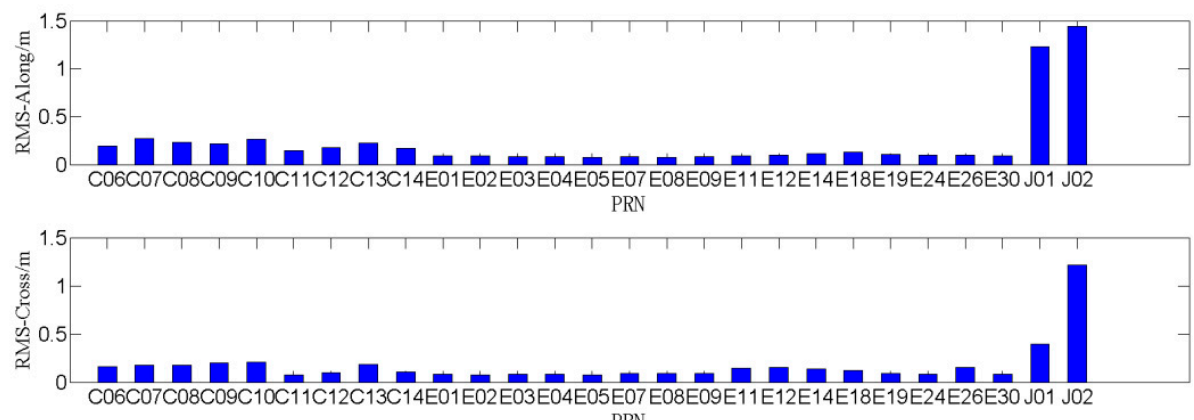

PRN

Figure 6. The RMS between the six-hour predicted orbits of the five-system ultra-rapid orbits and the orbits of GFZ for BDS, Galileo, and QZSS. 

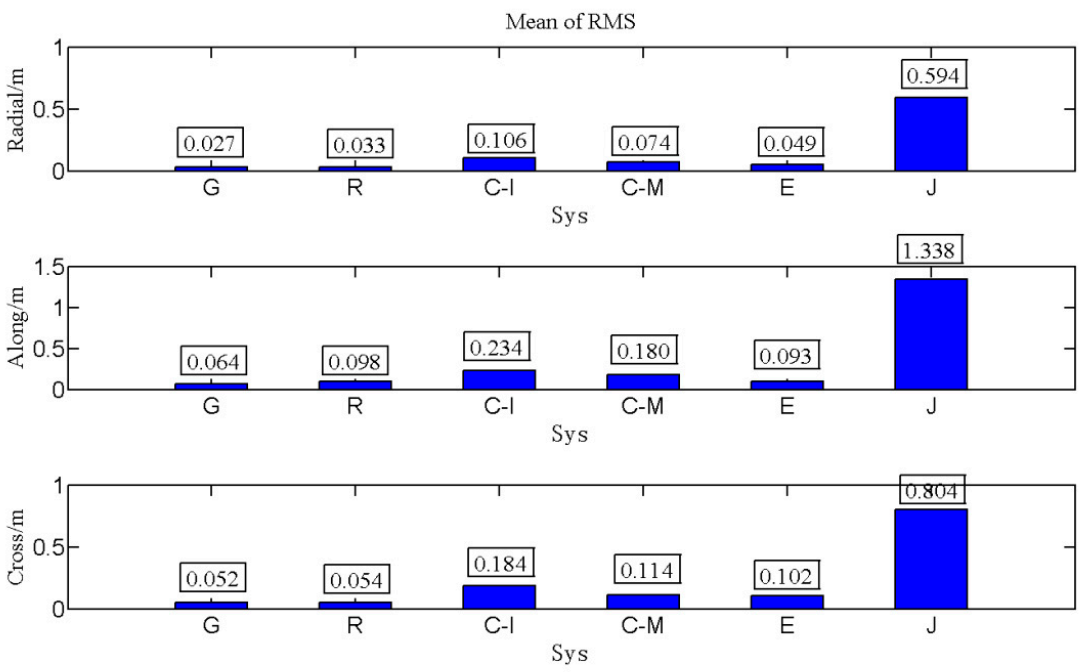

Figure 7. The mean of RMS between the six-hour predicted orbits of the five-system ultra-rapid orbits and the orbits of GFZ for five systems ( $\mathrm{I}=\mathrm{IGSO}, \mathrm{M}=\mathrm{MEO}$ ).

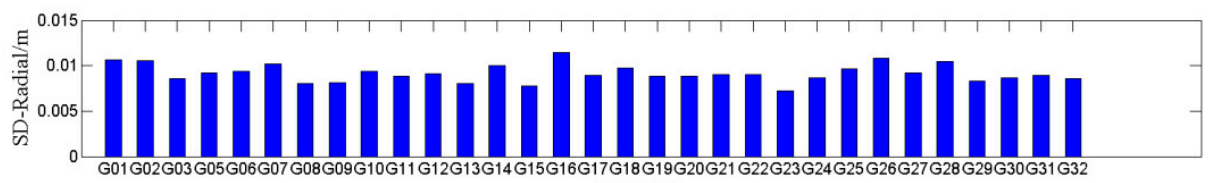
PRN-GPS

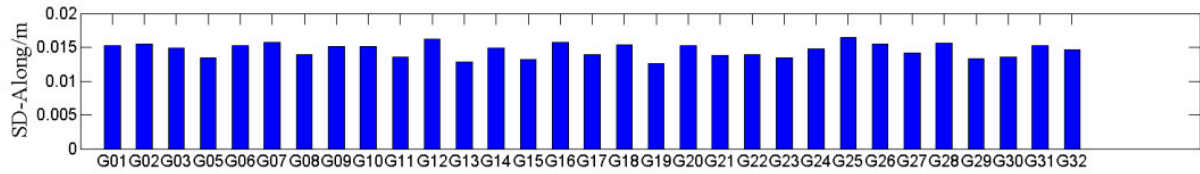
PRN-GPS

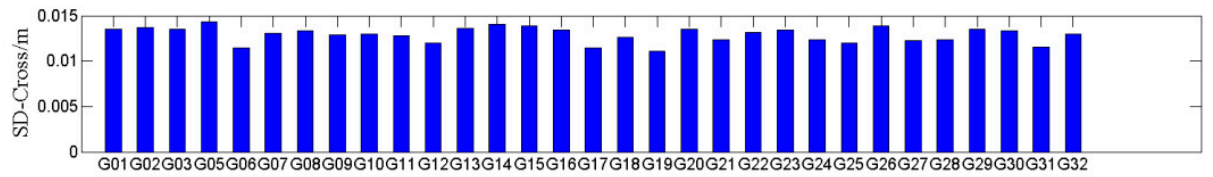
PRN-GPS

Figure 8. The standard deviations (SD) of the orbit discontinuities at day boundaries for GPS.

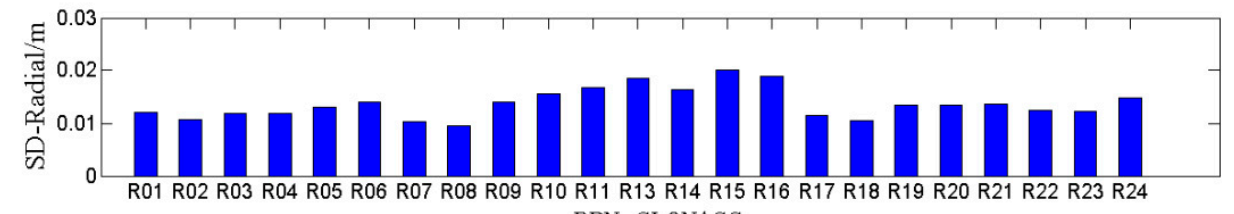
PRN-GLONASS
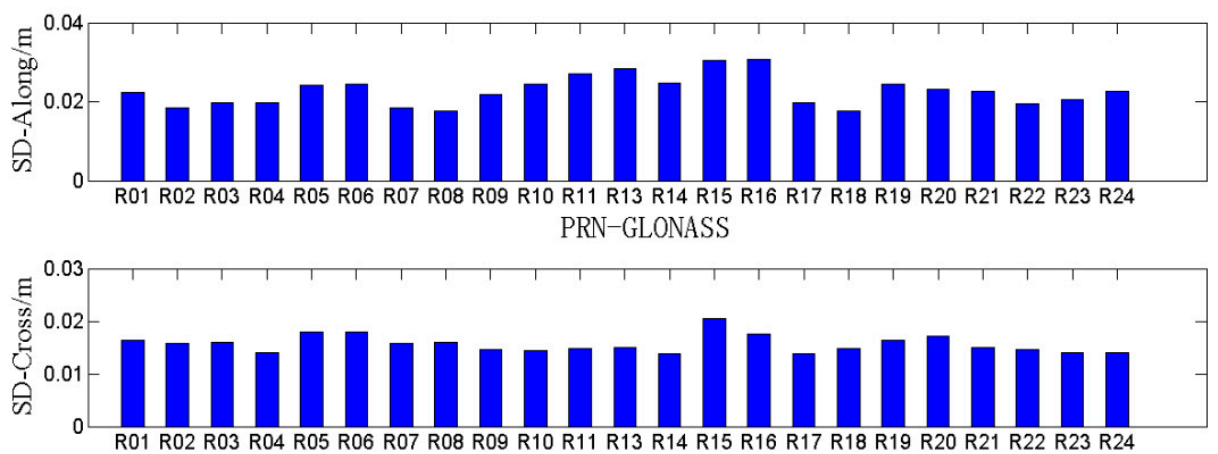
PRN-GLONASS

Figure 9. The SD of the orbit discontinuities at day boundaries for GLONASS. 

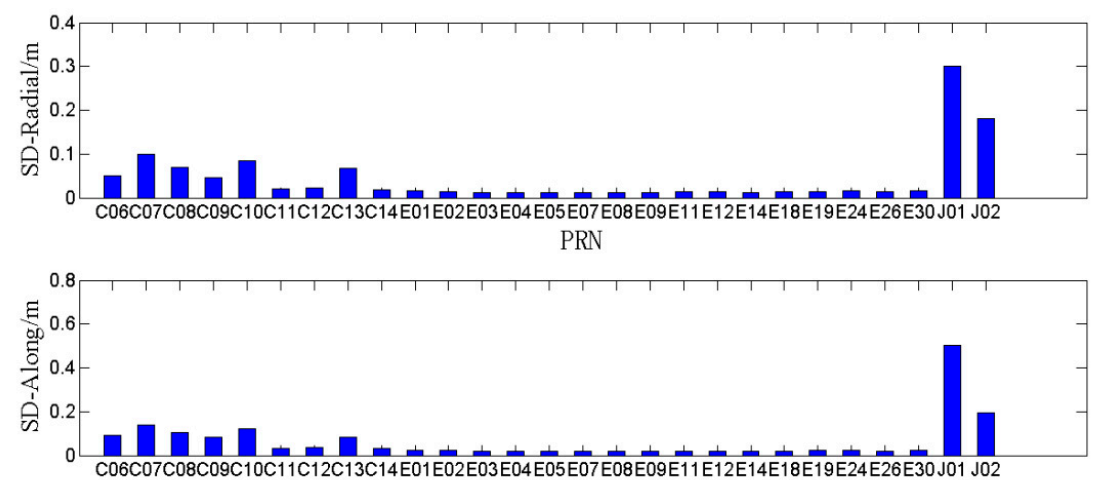

PRN

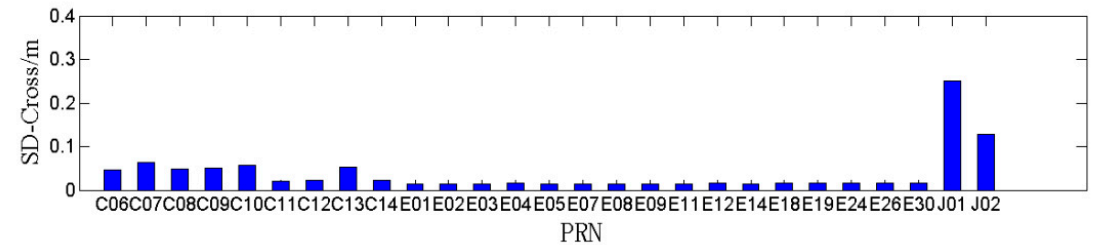

Figure 10. The SD of the orbit discontinuities at day boundaries for BDS, Galileo, and QZSS

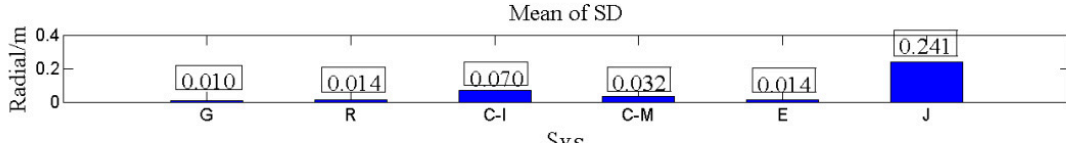

Sys

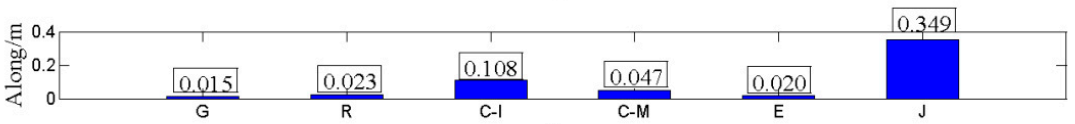

Sys

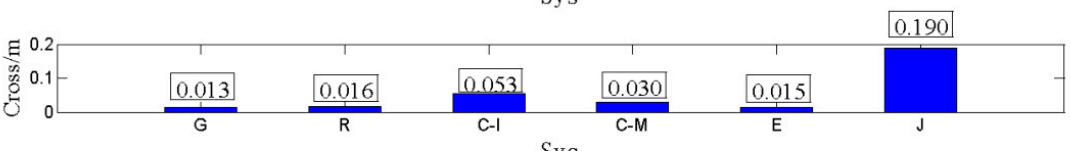

Sys

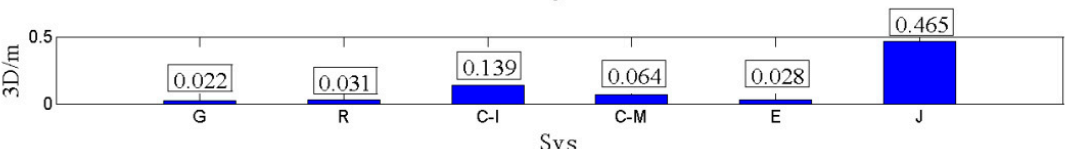

Sys

Figure 11. The mean of SD for five systems ( $\mathrm{I}=\mathrm{IGSO}, \mathrm{M}=\mathrm{MEO}, 3 \mathrm{D}=$ three dimension).
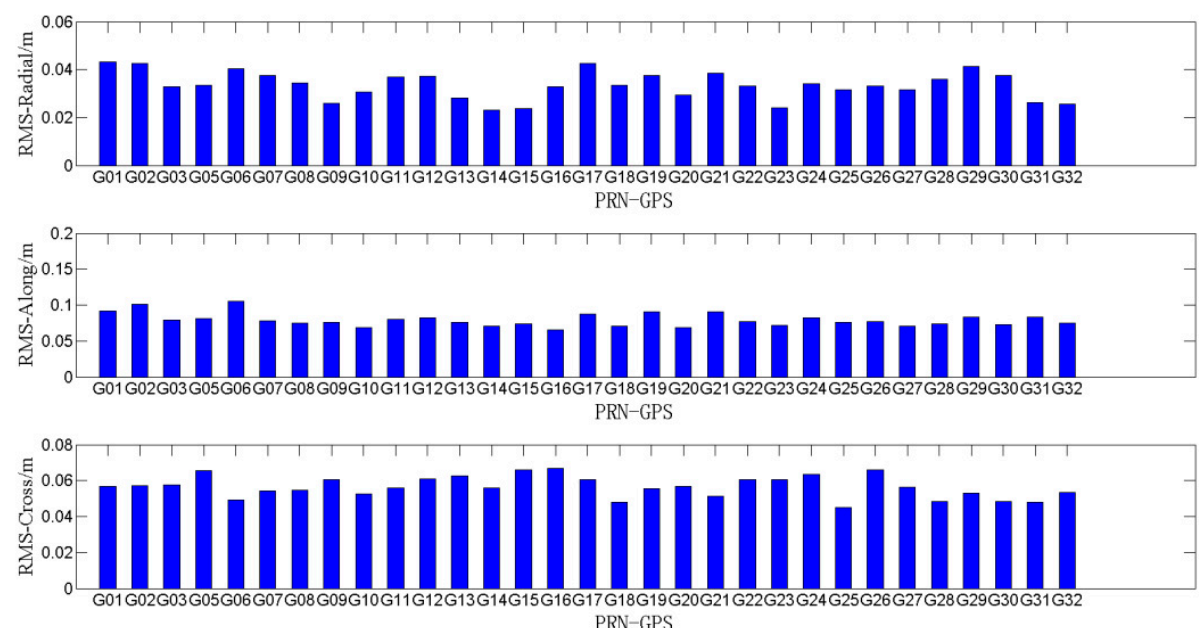

Figure 12. The RMS between the six-hour predicted orbits of IGGAC and the orbits of GFZ for GPS. 

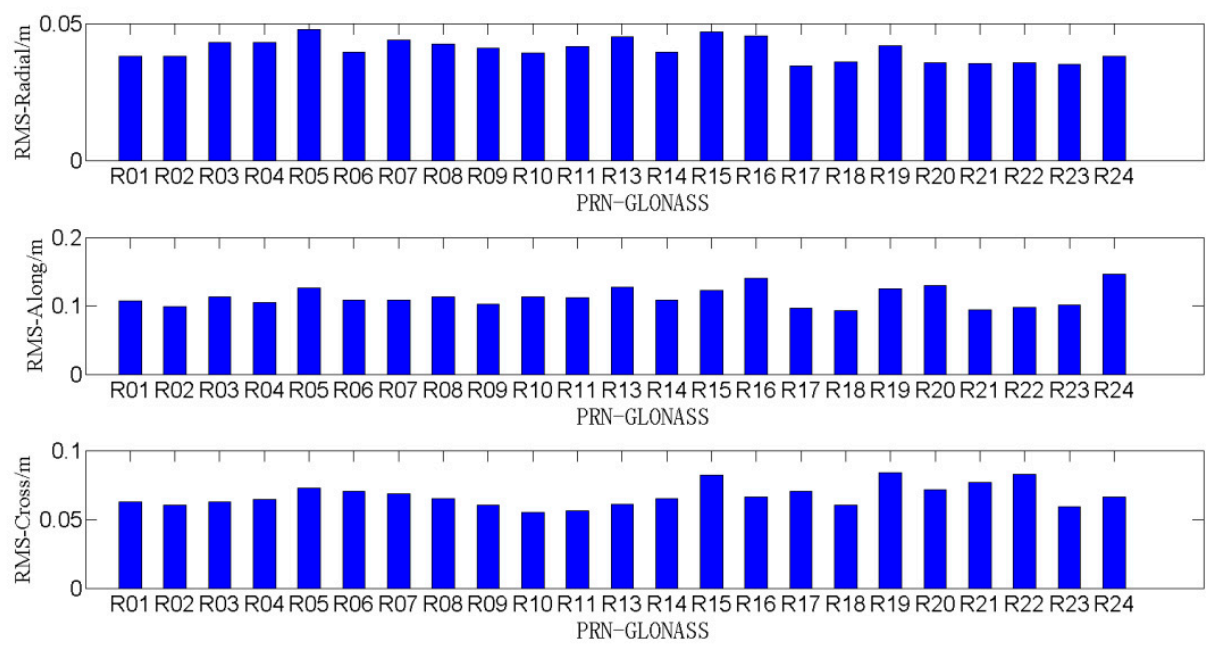

Figure 13. The RMS between the six-hour predicted orbits of IGGAC and the orbits of GFZ for GLONASS.
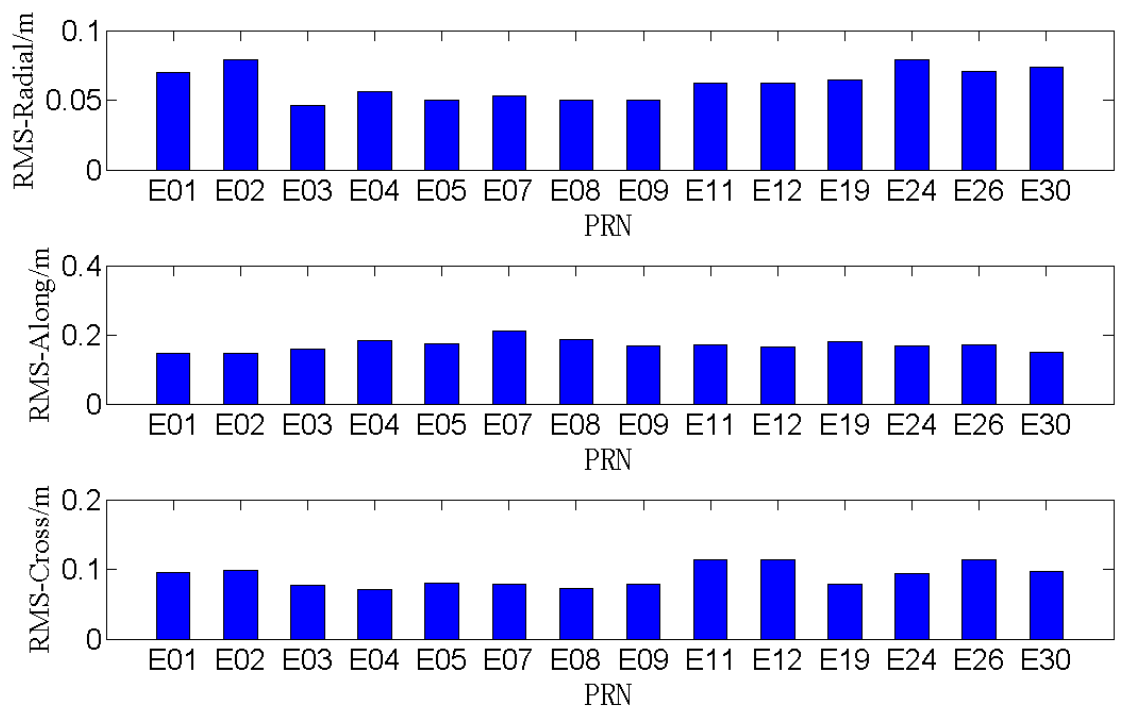

Figure 14. The RMS between the six-hour predicted orbits of IGGAC and the orbits of GFZ for Galileo.
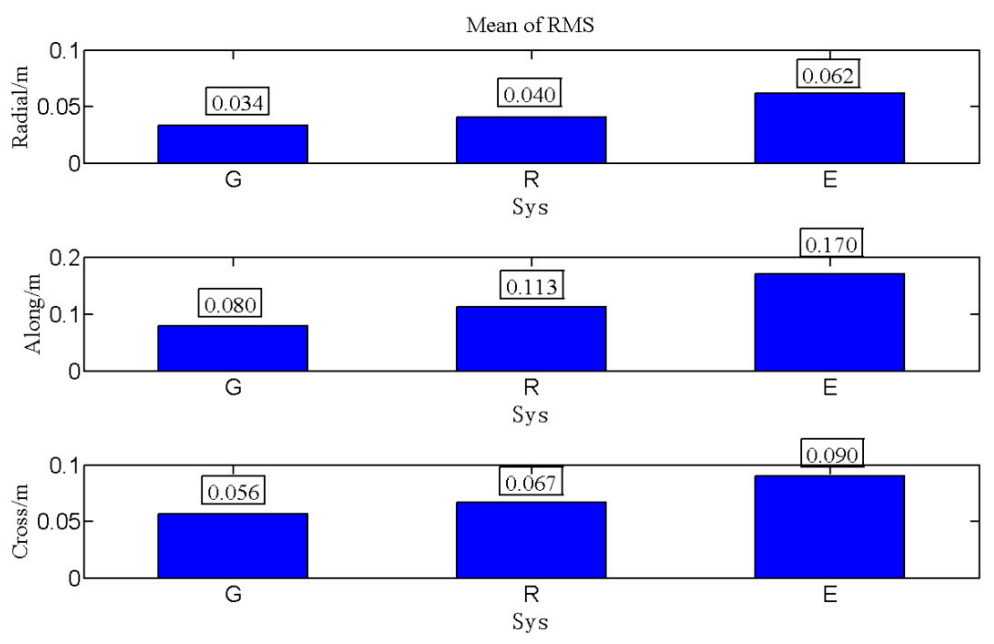

Figure 15. The mean of RMS between the six-hour predicted orbits of IGGAC and the orbits of GFZ for GPS, GLONASS, and Galieo. 
Based on the above calculations, we obtained the following test results. Figure 3 shows that the average time consumption for calculation was $2.02 \mathrm{~h}$; from Figures $4-7$, compared to the final MGEX orbit products of GFZ in the radial, along-track, and cross-track directions orbit components, for the six-hour predicted orbits of GPS satellites, the average RMSs were $0.027,0.064$, and $0.052 \mathrm{~m}$, respectively; for the six-hour predicted orbits of GLONASS satellites, the average RMSs were 0.033 , 0.098 , and $0.054 \mathrm{~m}$, respectively; for the six-hour predicted orbits of BDS IGSO satellites, the average RMSs were $0.106,0.234$, and $0.184 \mathrm{~m}$, respectively; for the six-hour predicted orbits of BDS MEO satellites, the average RMSs were $0.074,0.180$, and $0.114 \mathrm{~m}$, respectively; for the six-hour predicted orbits of Galileo satellites, the average RMSs were 0.049, 0.093, and $0.102 \mathrm{~m}$, respectively; for the six-hour predicted orbits of QZSS satellites, the average RMSs were 0.594, 1.338, and $0.804 \mathrm{~m}$, respectively; from Figures 8-11, analysis of the orbit discontinuities at day boundaries in the radial, along-track, and cross-track directions orbit components, for the six-hour predicted orbits of GPS satellites, the average SDs were $0.010,0.015$, and $0.013 \mathrm{~m}$ respectively; for the six-hour predicted orbits of GLONASS satellites, the average SDs were $0.014,0.023$, and $0.016 \mathrm{~m}$ respectively; for the six-hour predicted orbits of BDS IGSO satellites, the average SDs were $0.070,0.108$, and $0.053 \mathrm{~m}$, respectively; for the six-hour predicted orbits of BDS MEO satellites, the average SDs were $0.032,0.047$, and $0.030 \mathrm{~m}$, respectively; for the six-hour predicted orbits of Galileo satellites, the average SDs were $0.014,0.020$, and $0.015 \mathrm{~m}$, respectively; for the six-hour predicted orbits of QZSS satellites, the average SDs were $0.241,0.349$, and $0.190 \mathrm{~m}$, respectively; from Figures $12-15$, comparison between IGGAC and the final MGEX orbit products of GFZ in the radial, along-track, and cross-track directions orbit components, for the six-hour predicted orbits of GPS satellites, the average RMSs were $0.034,0.080$, and $0.056 \mathrm{~m}$ respectively; for the six-hour predicted orbits of GLONASS satellites, the average RMSs were 0.040, 0.113 , and $0.067 \mathrm{~m}$, respectively; for the six-hour predicted orbits of Galileo satellites, the average RMSs were $0.062,0.170$, and $0.090 \mathrm{~m}$, respectively.

\section{Discussion}

According to the above results of the orbit discontinuities at day boundaries, for the three-dimensional SDs, we can know that they are about 3, 6, 14, and $47 \mathrm{~cm}$ for GPS/GLONASS/Galileo, BDS MEO, BDS IGSO, and QZSS satellites, respectively. This shows that the performance to process IGSO satellites of this new prototype software platform needs to be improved compared with MEO satellites. Besides, for the results of step (2) in Section 3, considering the orbit assessment results of GFZ, which was based on the one-step method and no-difference observation model [52], we can know that the double-difference observation model of five systems and the no-difference observation model of five systems have good consistency. In addition, by analyzing the results of step (2) and (4) in Section 3, compared to the orbits provided by the software package of IGGAC, we can know that the consistency of the results calculated by this new prototype software platform is significantly improved in the radial, along-track, cross-track, and 3D directions.

As mentioned above, our new prototype software platform is only a preliminary state. In view of the fact that only the orbits of non-GEO satellites were tested in this paper, the performance of our new prototype software platform in processing the orbit of GEO satellites needs to be further verified. Besides this, the new prototype software platform did not build a special attitude model and SRP model for the orbit normal mode, which is worth further improvement. 


\section{Conclusions}

In this study, we derived the double-difference observation model of the GPS/GLONASS/BDS/ Galileo/QZSS five-system ultra-rapid POD based on the one-step method. Additionally, using the framework of Bernese v5.2 and this model and method, we developed a new prototype software platform for five-system ultra-rapid precise orbit calculation. Subsequently, one month of real tracking data collected from 130 globally distributed IGS MGEX stations were used to test the software platform. The results show that this new prototype software platform has the preliminary function of processing five-system ultra-rapid orbits. In terms of the analysis of the orbit discontinuities at day boundaries, the average SDs in 3D were $0.022,0.031,0.139,0.064,0.028$, and $0.465 \mathrm{~m}$ for GPS, GLONASS, BDS IGSO, BDS MEO, Galileo, and QZSS satellites, respectively. Besides, based on the one-step method, the double-difference observation model of five systems and the no-difference observation model of five systems have good consistency. Compared to the ultra-rapid orbits of IGGAC, in 3D direction of orbit consistency with the final MGEX orbit products of GFZ, the improved percentages of this new prototype software platform were 78.51\%, $77.19 \%$, and $85.82 \%$ for GPS, GLONASS, and Galileo satellites, respectively. The consistency in other directions has also improved significantly.

Author Contributions: F.Y., Y.Y. provided the initial idea for this study; F.Y., Y.Y., and B.T. developed the new prototype software platform; F.Y., Z.D., and B.T. conceived and designed the experiments; F.Y., Y.Y., Z.D., B.T., and J.O. analyzed the experiment results; F.Y., Y.Y., Z.D., and B.T. wrote the paper.

Funding: This work was supported by the Collaborative Precision Positioning Project funded by the Ministry of Science and Technology of China (No. 2016YFB0501900) and China Natural Science Funds (No. 41674022, $41574015,41574033)$.

Acknowledgments: The authors also acknowledge LU JIAXI International team program supported by the K.C. Wong Education Foundation and CAS. The authors would like to thank the IGS MGEX and Chinese iGMAS networks for providing the Multi-GNSS data. The authors would like to thank the CODE for providing the Bernese v5.2. Thanks to Rolf Dach and Maorong Ge for giving careful answers in developing software platform. Thanks to Baocheng Zhang, Qingsong Ai and Peizhao Liu for giving careful guidance in modifying this article.

Conflicts of Interest: The authors declare no conflict of interest.

\section{Appendix A}

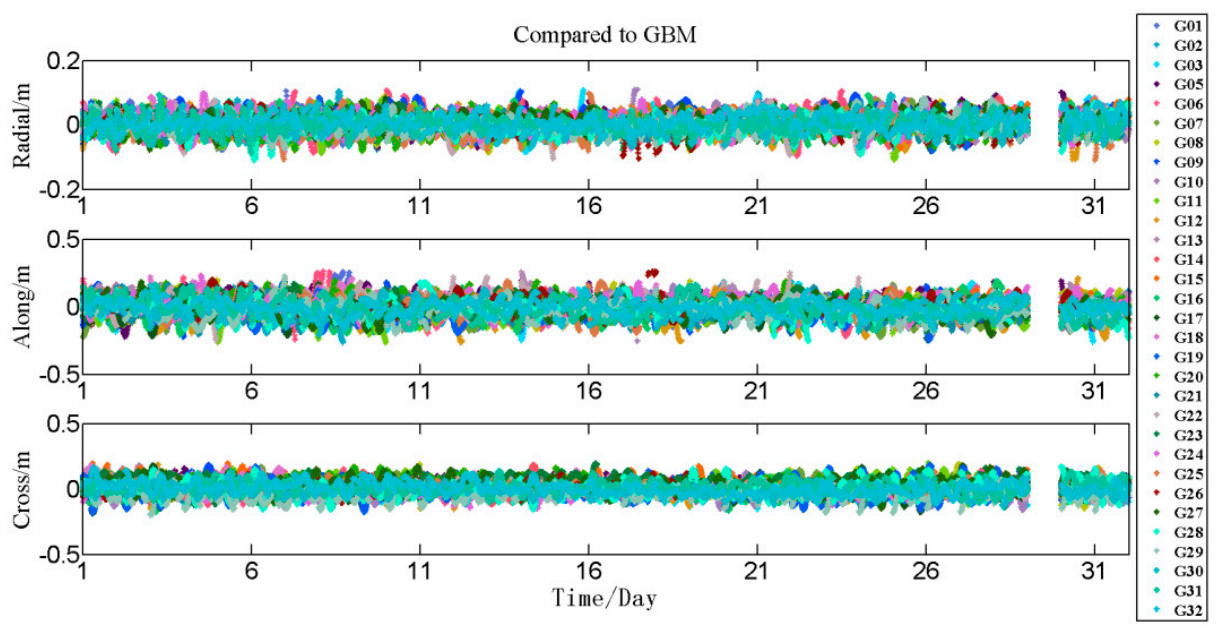

Figure A1. The differences between the six-hour predicted orbits of five-system ultra-rapid orbits and the orbits of GFZ for GPS. 


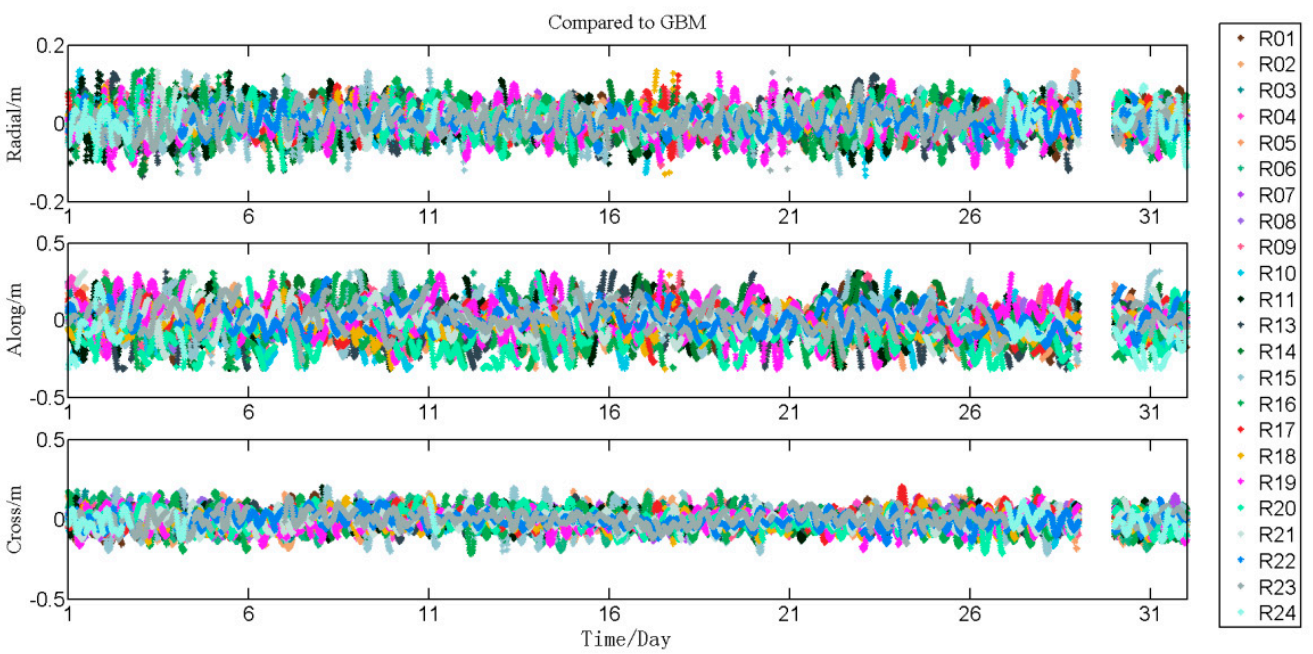

Figure A2. The differences between the six-hour predicted orbits of five-system ultra-rapid orbits and the orbits of GFZ for GLONASS.
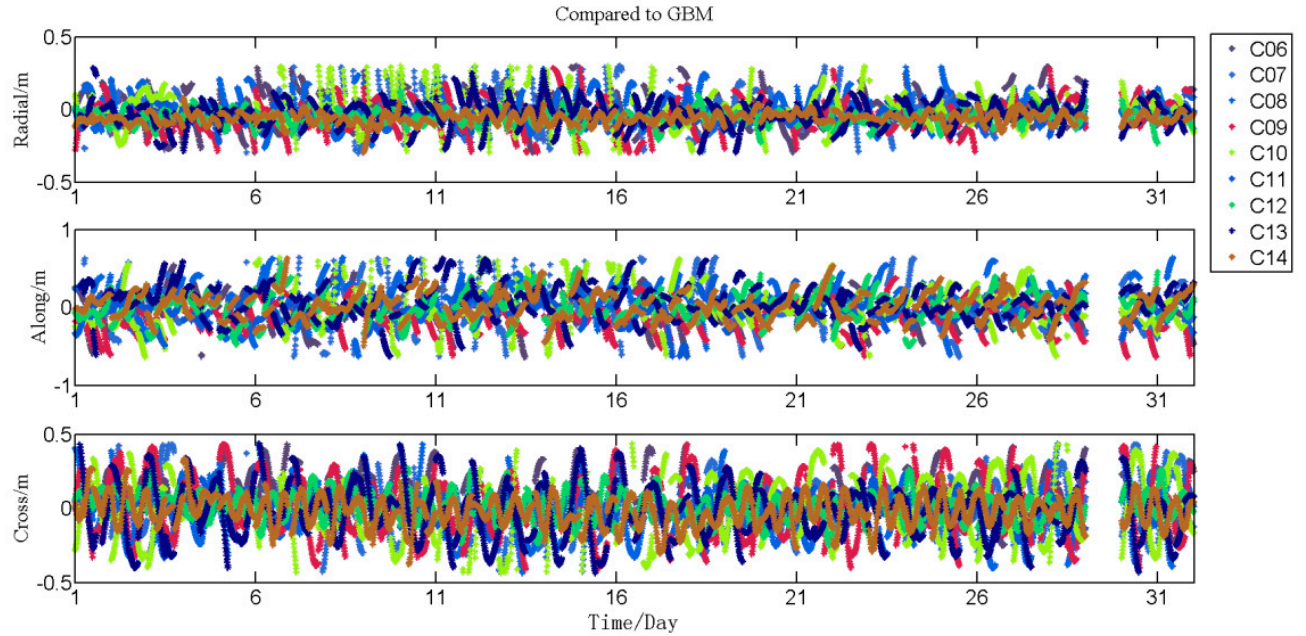

Figure A3. The differences between the six-hour predicted orbits of five-system ultra-rapid orbits and the orbits of GFZ for BDS.

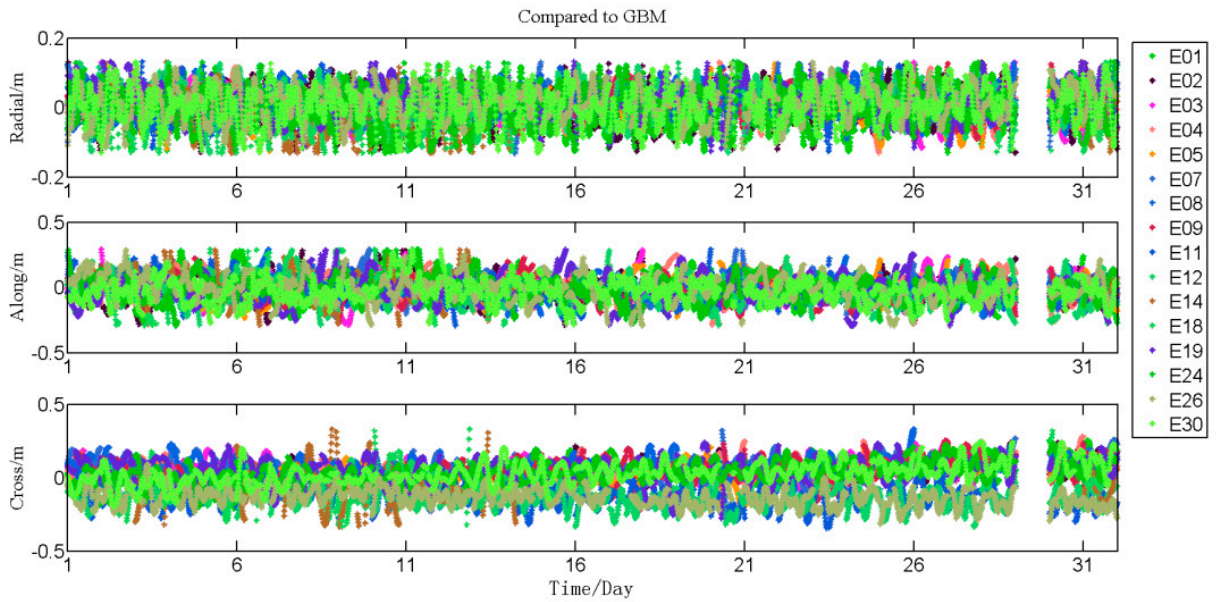

Figure A4. The differences between the six-hour predicted orbits of five-system ultra-rapid orbits and the orbits of GFZ for Galileo. 

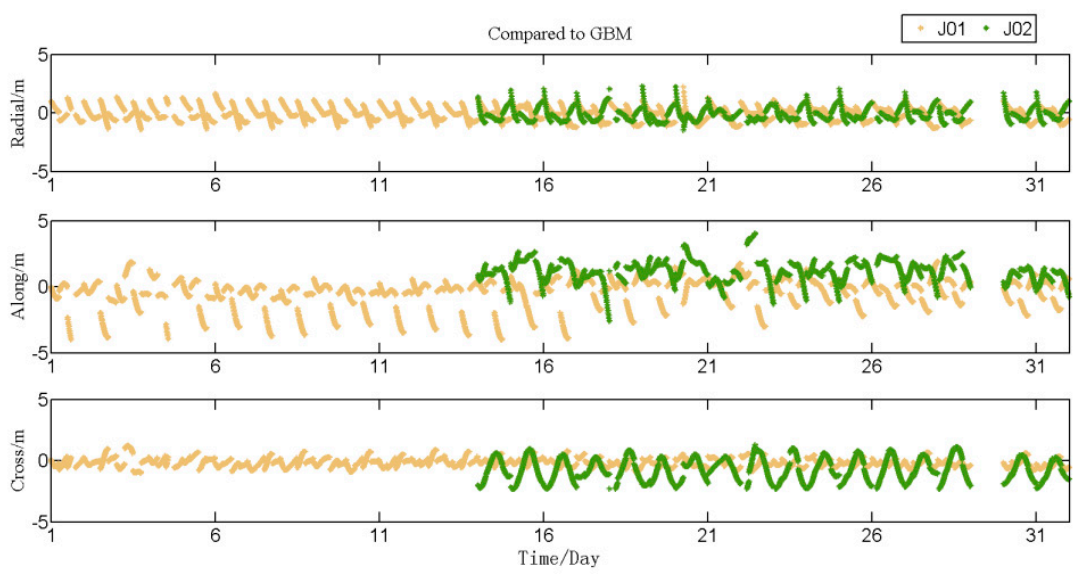

Figure A5. The differences between the six-hour predicted orbits of five-system ultra-rapid orbits and the orbits of GFZ for QZSS.

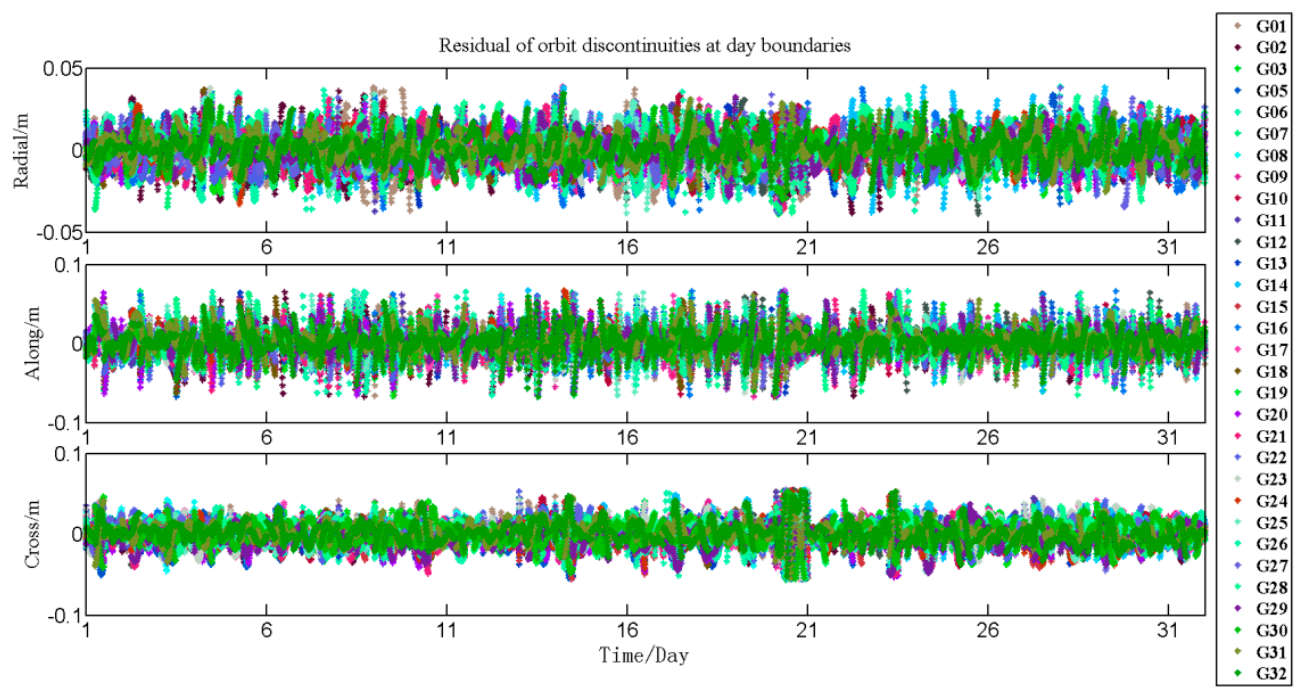

Figure A6. The residuals of the orbit discontinuities at day boundaries for GPS.

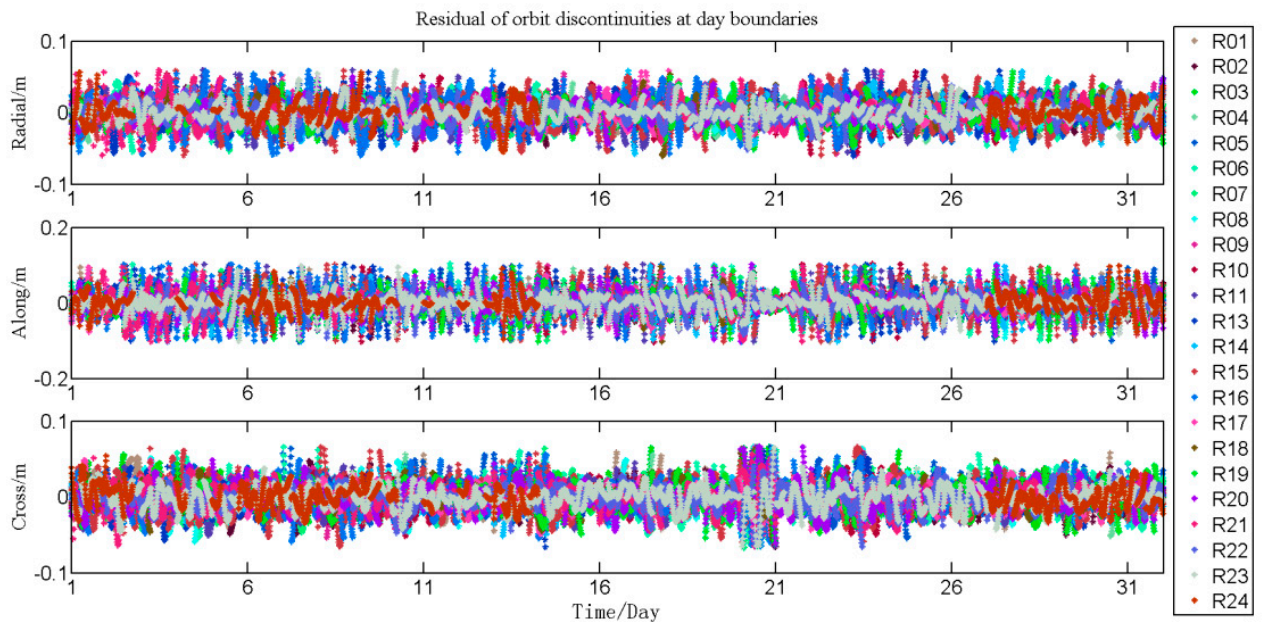

Figure A7. The residuals of the orbit discontinuities at day boundaries for GLONASS. 

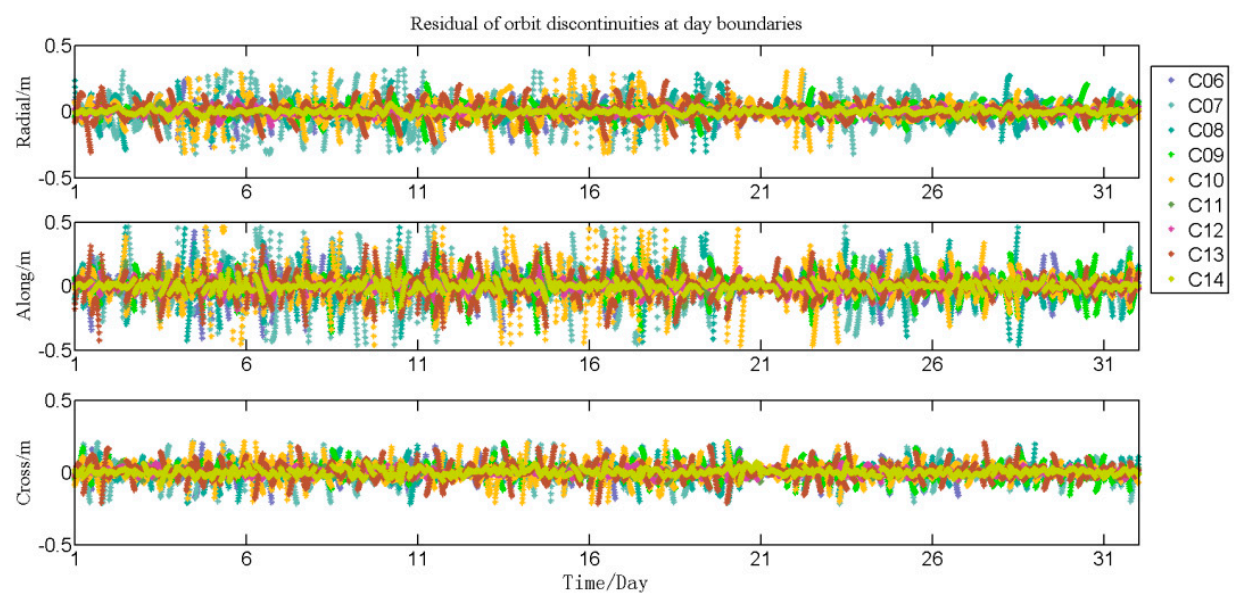

Figure A8. The residuals of the orbit discontinuities at day boundaries for BDS.
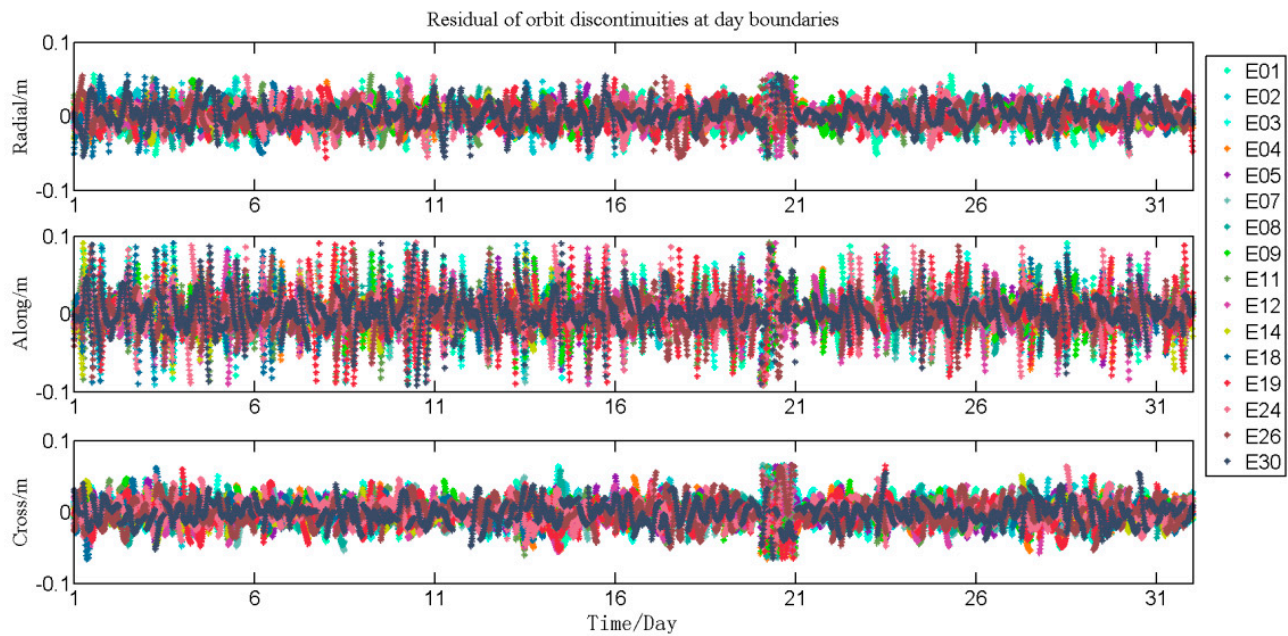

Figure A9. The residuals of the orbit discontinuities at day boundaries for Galileo.
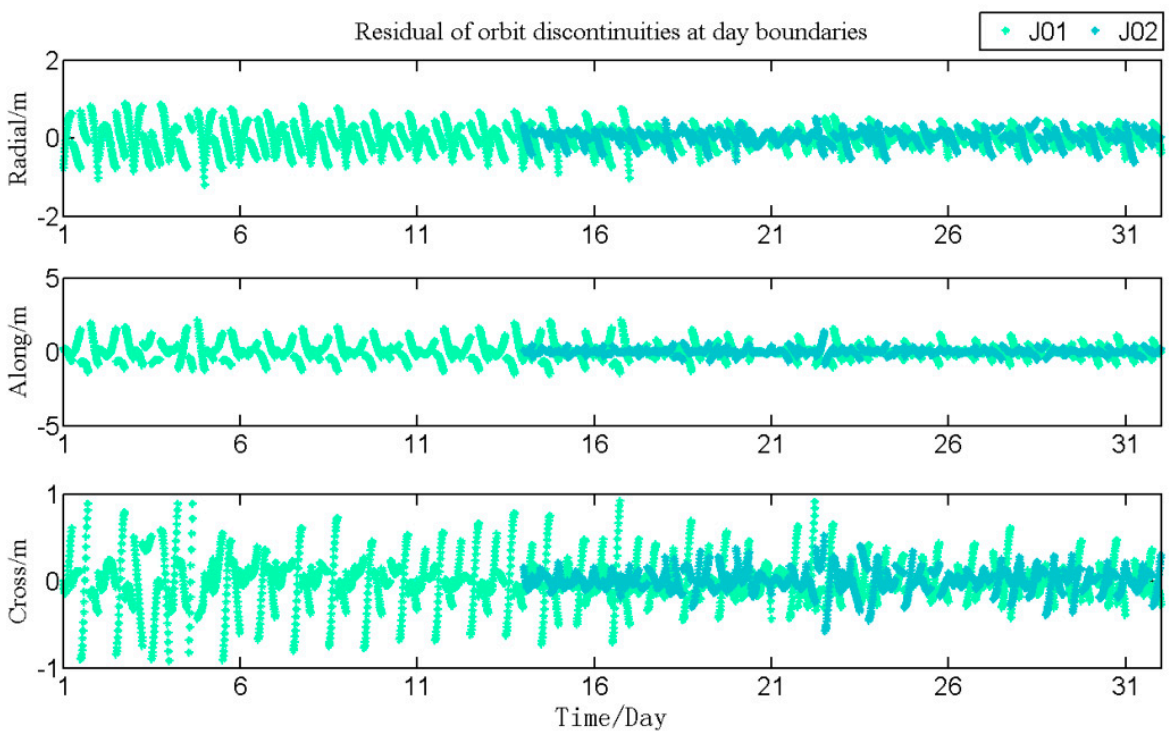

Figure A10. The residuals of the orbit discontinuities at day boundaries for QZSS. 


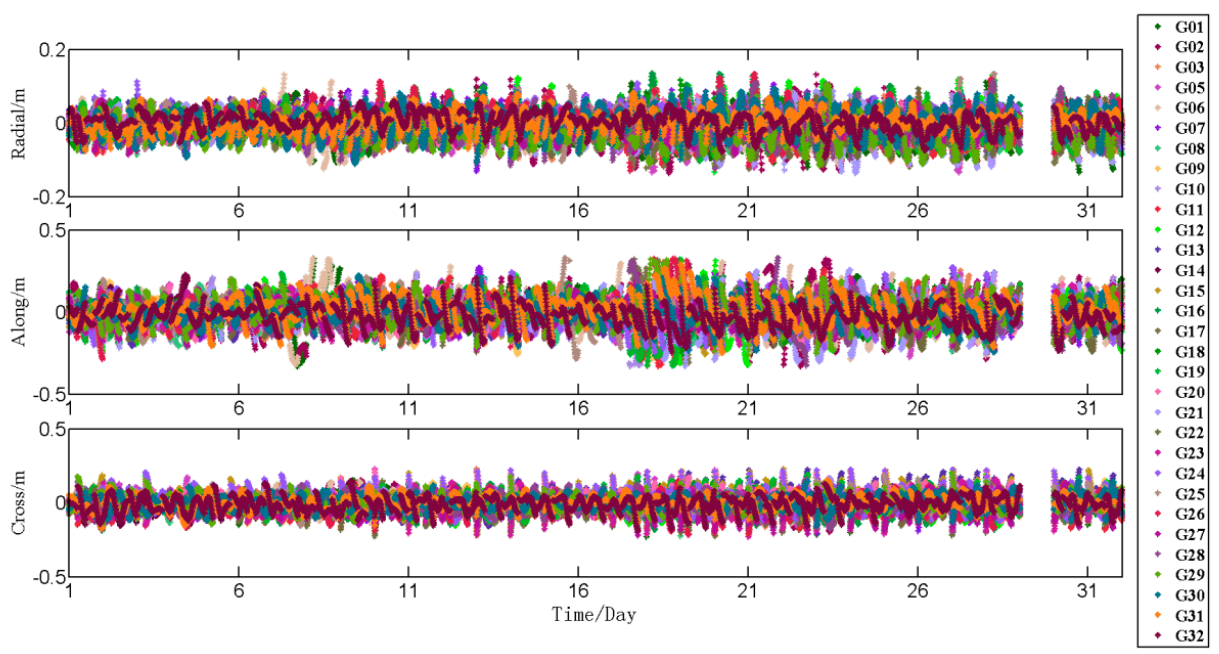

Figure A11. The differences between the six-hour predicted orbits of IGGAC and the orbits of GFZ for GPS.

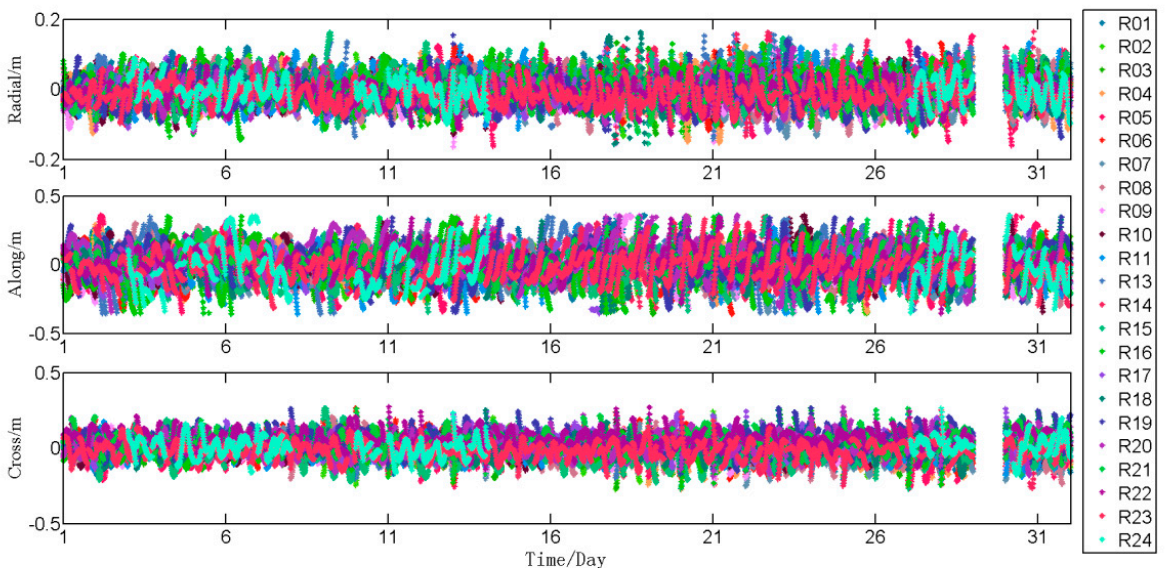

Figure A12. The differences between the six-hour predicted orbits of IGGAC and the orbits of GFZ for GLONASS.
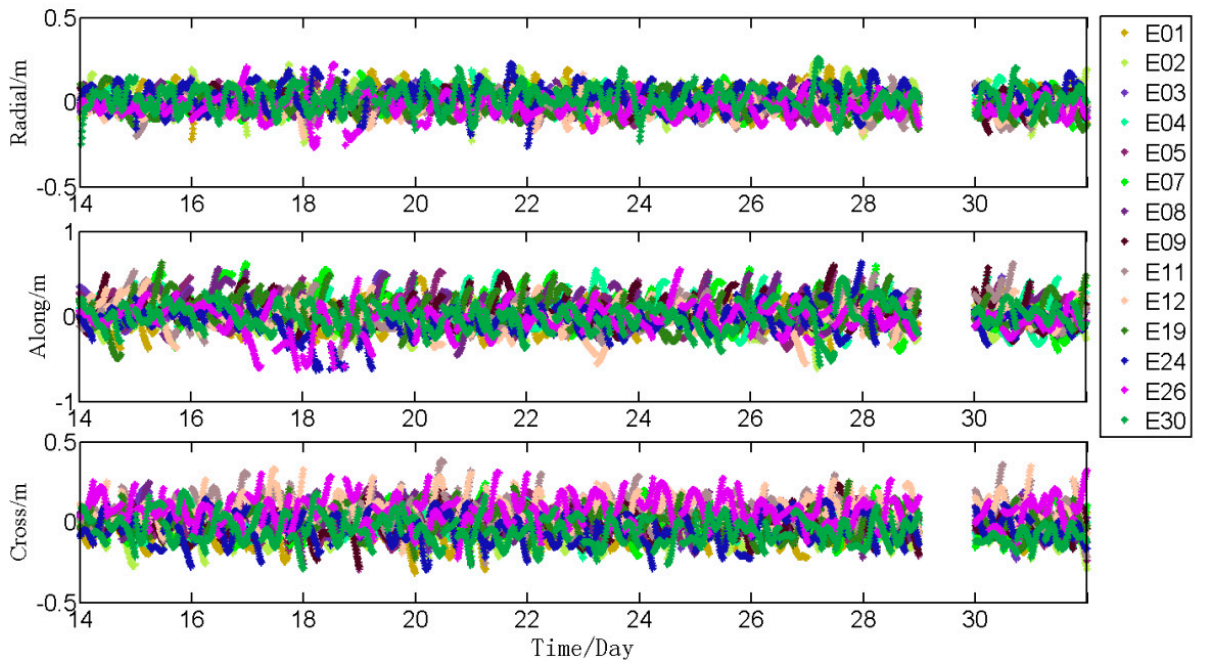

Figure A13. The differences between the six-hour predicted orbits of IGGAC and the orbits of GFZ for Galileo. 
Table A1. The differences between the results of our new prototype software platform and IGGAC in consistency with the final MGEX orbit products of GFZ.

\begin{tabular}{ccccc}
\hline Items & & $\begin{array}{c}\text { The New Prototype } \\
\text { Software Platform }(\mathbf{m})\end{array}$ & $\begin{array}{c}\text { IGGAC } \\
(\mathbf{m})\end{array}$ & $\begin{array}{c}\text { Improved } \\
\text { Percentage }(\mathbf{\%})\end{array}$ \\
\hline \multirow{6}{*}{ GPS } & Radial & 0.010 & 0.034 & 70.59 \\
& Along & 0.015 & 0.080 & 81.25 \\
& Cross & 0.013 & 0.056 & 76.79 \\
\multirow{6}{*}{ GLONASS } & 3D & 0.022 & 0.103 & 78.51 \\
\hline \multirow{6}{*}{ Galileo } & Radial & 0.014 & 0.040 & 65.00 \\
& Along & 0.023 & 0.113 & 79.65 \\
& Cross & 0.016 & 0.067 & 76.12 \\
& 3D & 0.031 & 0.137 & 77.19 \\
\hline & Radial & 0.014 & 0.062 & 77.42 \\
& Along & 0.020 & 0.170 & 88.24 \\
& Cross & 0.015 & 0.090 & 83.33 \\
\hline
\end{tabular}

\section{References}

1. Montenbruck, O.; Steigenberger, P.; Prange, L.; Deng, Z.G.; Zhao, Q.L.; Perosanz, F.; Romero, I.; Noll, C.; Sturze, A.; Weber, G.; et al. The Multi-GNSS Experiment (MGEX) of the International GNSS Service (IGS)_Achievements, prospects and challenges. Adv. Space Res. 2017, 59, 1671-1697. [CrossRef]

2. Montenbruck, O.; Steigenberger, P.; Hauschild, A. Broadcast versus precise ephemerides: A multi-GNSS perspective. GPS Solut. 2015, 19, 321-333. [CrossRef]

3. Harnisch, F.; Healy, S.B.; Bauer, P.; English, S.J. Scaling of GNSS Radio Occultation Impact with Observation Number Using an Ensemble of Data Assimilations. Mon. Weather Rev. 2013, 141, 4395-4413. [CrossRef]

4. Zhao, C.; Yuan, Y.; Zhang, B.; Li, M. Ionosphere Sensing with a Low-Cost, Single-Frequency, Multi-GNSS Receiver. IEEE Trans. Geosci. Remote Sens. 2018, 1-12. [CrossRef]

5. Li, X.; Zus, F.; Lu, C.; Dick, G.; Ning, T.; Ge, M.; Wickert, J.; Schuh, H. Retrieving of atmospheric parameters from multi-GNSS in real time: Validation with water vapor radiometer and numerical weather model. J. Geophys. Res.-Atmos. 2015, 120, 7189-7204. [CrossRef]

6. Guo, F.; Li, X.; Zhang, X.; Wang, J. Assessment of precise orbit and clock products for Galileo, BeiDou, and QZSS from IGS Multi-GNSS Experiment (MGEX). GPS Solut. 2017, 21, 279-290. [CrossRef]

7. Guo, F.; Li, X.X.; Zhang, X.H.; Wang, J.L. The contribution of Multi-GNSS Experiment (MGEX) to precise point positioning. Adv. Space Res. 2017, 59, 2714-2725. [CrossRef]

8. Li, X.; Ge, M.; Dai, X.; Ren, X.; Fritsche, M.; Wickert, J.; Schuh, H. Accuracy and reliability of multi-GNSS real-time precise positioning: GPS, GLONASS, BeiDou, and Galileo. J. Geod. 2015, 89, 607-635. [CrossRef]

9. Li, B.F.; Li, Z.; Zhang, Z.T.; Tan, Y.A. ERTK: Extra-wide-lane RTK of triple-frequency GNSS signals. J. Geod. 2017, 91, 1031-1047. [CrossRef]

10. Odolinski, R.; Teunissen, P.J.G.; Odijk, D. Combined BDS, Galileo, QZSS and GPS single-frequency RTK. GPS Solut. 2015, 19, 151-163. [CrossRef]

11. Lutz, S.; Meindl, M.; Steigenberger, P.; Beutler, G.; Sosnica, K.; Schaer, S.; Dach, R.; Arnold, D.; Thaller, D.; Jaeggi, A. Impact of the arc length on GNSS analysis results. J. Geod. 2016, 90, 365-378. [CrossRef]

12. Bury, G.; Sośnica, K.; Zajdel, R. Multi-GNSS orbit determination using satellite laser ranging. J. Geod. 2018. [CrossRef]

13. Loyer, S.; Perosanz, F.; Mercier, F.; Capdeville, H.; Marty, J.-C. Zero-difference GPS ambiguity resolution at CNES-CLS IGS Analysis Center. J. Geod. 2012, 86, 991-1003. [CrossRef]

14. Prange, L.; Dach, R.; Lutz, S.; Schaer, S.; Jäggi, A. The CODE MGEX Orbit and Clock Solution; Springer: Cham, Switzerland, 2015; pp. 767-773.

15. Uhlemann, M.; Gendt, G.; Ramatschi, M.; Deng, Z. GFZ Global Multi-GNSS Network and Data Processing Results; Springer: Cham, Switzerland, 2015; pp. 673-679. 
16. Steigenberger, P.; Hugentobler, U.; Loyer, S.; Perosanz, F.; Prange, L.; Dach, R.; Uhlemann, M.; Gendt, G.; Montenbruck, O. Galileo orbit and clock quality of the IGS Multi-GNSS Experiment. Adv. Space Res. 2015, 55, 269-281. [CrossRef]

17. Springer, T.; Otten, M.; Flohrer, C. Spreading the usage of NAPEOS, the ESA tool for satellite geodesy. In Proceedings of the EGU General Assembly Conference Abstracts, Vienna, Austria, 22-27 April 2012.

18. Guo, J.; Xu, X.; Zhao, Q.; Liu, J. Precise orbit determination for quad-constellation satellites at Wuhan University: Strategy, result validation, and comparison. J. Geod. 2016, 90, 143-159. [CrossRef]

19. Kasho, S. Accuracy evaluation of QZS-1 precise ephemerides with satellite laser ranging. In Proceedings of the 19th International Workshop on Laser Ranging, Annapolis, MD, USA, 27-31 October 2014; p. 30.

20. Prange, L.; Orliac, E.; Dach, R.; Arnold, D.; Beutler, G.; Schaer, S.; Jäggi, A. CODE's five-system orbit and clock solution-The challenges of multi-GNSS data analysis. J. Geod. 2017, 91, 345-360. [CrossRef]

21. Steigenberger, P.; Hugentobler, U.; Montenbruck, O.; Hauschild, A. Precise orbit determination of GIOVE-B based on the CONGO network. J. Geod. 2011, 85, 357-365. [CrossRef]

22. Li, X.; Yuan, Y.; Zhu, Y.; Huang, J.; Wu, J.; Xiong, Y.; Zhang, X.; Li, X. Precise orbit determination for BDS3 experimental satellites using iGMAS and MGEX tracking networks. J. Geod. 2018. [CrossRef]

23. Springer, T.A.; Hugentobler, U. IGS ultra rapid products for (near-) real-time applications. Phys. Chem. Earth Part A-Solid Earth Geod. 2001, 26, 623-628. [CrossRef]

24. Ray, J.; Griffiths, J. Status of IGS ultra-rapid products for realtime applications. In Proceedings of the 2008 AGU Fall Meeting, San Francisco, CA, USA, 15-19 December 2008; p. 18.

25. Choi, K.K.; Ray, J.; Griffiths, J.; Bae, T.-S. Evaluation of GPS orbit prediction strategies for the IGS Ultra-rapid products. GPS Solut. 2013, 17, 403-412. [CrossRef]

26. Dousa, J. Precise orbits for ground-based GPS meteorology: Processing strategy and quality assessment of the orbits determined at geodetic observatory Pecny. J. Meteorol. Soc. Jpn. 2004, 82, 371-380. [CrossRef]

27. Lutz, S.; Beutler, G.; Schaer, S.; Dach, R.; Jaeggi, A. CODE's new ultra-rapid orbit and ERP products for the IGS. GPS Solut. 2016, 20, 239-250. [CrossRef]

28. Li, X.; Chen, X.; Ge, M.; Schuh, H. Improving multi-GNSS ultra-rapid orbit determination for real-time precise point positioning. J. Geod. 2018. [CrossRef]

29. Hadas, T.; Krypiak-Gregorczyk, A.; Hernandez-Pajares, M.; Kaplon, J.; Paziewski, J.; Wielgosz, P.; Garcia-Rigo, A.; Kazmierski, K.; Sosnica, K.; Kwasniak, D.; et al. Impact and Implementation of Higher-Order Ionospheric Effects on Precise GNSS Applications. J. Geophys. Res.-Solid Earth. 2017, 122, 9420-9436. [CrossRef]

30. Beutler, G.; Brockmann, E.; Gurtner, W.; Hugentobler, U.; Mervart, L.; Rothacher, M.; Verdun, A. Extended orbit modeling techniques at the CODE processing center of the international GPS service for geodynamics (IGS): Theory and initial results. Manuscr. Geod. 1994, 19, 367-386.

31. Arnold, D.; Meindl, M.; Beutler, G.; Dach, R.; Schaer, S.; Lutz, S.; Prange, L.; Sośnica, K.; Mervart, L.; Jäggi, A. CODE's new solar radiation pressure model for GNSS orbit determination. J. Geod. 2015, 89, 775-791. [CrossRef]

32. Dach, R.; Lutz, S.; Walser, P.; Fridez, P. Bernese GNSS Software Version 5.2; University of Bern, Bern Open Publishing: Bern, Switzerland, 2015; p. 174.

33. IGS, RTCM-SC104. RINEX: The Receiver Independent Exchange Format, Version 3.02; Technical Report; IGS Central Bureau: Kwun Tong, Hong Kong, 2013.

34. Interface Specifcation I.S. GPS-200, Revision D, Navstar GPS Space Segment/Navigation User Interfaces; Navstar Joint Program Office: El Segundo, CA, USA, 2004.

35. Glonass ICD. Glonass Interface Control Document; Russian Institute of Space Device Engineering: Moscow, Russia, 2008.

36. ICD BDS. BeiDou Navigation Satellite System Signal in Space Interface Control Document; China Satellite Navigation Office: Changdou, China, 2013; p. 12.

37. European Union. European GNSS (Galileo) Open Service: Signal in Space Interface Control Document; Office for Official Publications of the European Communities: Brussels, Belgium, 2010.

38. Quasi-Zenith Satellite System Navigation Service, Interface Specifications for QZSS (IS-QZSSVer 1.2). Available online: http:/ / qzss.jaxa.jp/isqzss/index_e.html (accessed on 28 November 2014).

39. Yang, Y.; Lu, M.; Han, C. Some notes on interoperability of GNSS. Acta Geod. Cartogr. Sin. 2016, 45, $253-259$. [CrossRef] 
40. Sośnica, K.; Prange, L.; Kaźmierski, K.; Bury, G.; Drożdżewski, M.; Zajdel, R.; Hadas, T. Validation of Galileo orbits using SLR with a focus on satellites launched into incorrect orbital planes. J. Geod. 2018, 92, 131-148. [CrossRef]

41. Montenbruck, O.; Schmid, R.; Mercier, F.; Steigenberger, P.; Noll, C.; Fatkulin, R.; Kogure, S.; Ganeshan, A.S. GNSS satellite geometry and attitude models. Adv. Space Res. 2015, 56, 1015-1029. [CrossRef]

42. Boehm, J.; Heinkelmann, R.; Schuh, H. Short Note: A global model of pressure and temperature for geodetic applications. J. Geod. 2007, 81, 679-683. [CrossRef]

43. Boehm, J.; Niell, A.; Tregoning, P.; Schuh, H. Global Mapping Function (GMF): A new empirical mapping function based on numerical weather model data. Geophys. Res. Lett. 2006, 33, L07304. [CrossRef]

44. Luzum, B.J.; Ray, J.R.; Carter, M.S.; Josties, F.J. Recent Improvements to IERS Bulletin A Combination and Prediction. GPS Solut. 2001, 4, 34-40. [CrossRef]

45. Pavlis, N.K.; Holmes, S.A.; Kenyon, S.C.; Factor, J.K. The Development and Evaluation of the Earth Gravitational Model 2008 (EGM2008) (vol 117, B04406, 2012). J. Geophys. Res.-Solid Earth. 2013, 118, 2633. [CrossRef]

46. Petit, G.; Luzum, B. IERS Conventions (2010); Bureau International des Poids et Mesures Sevres: Sèvres, France, 2010.

47. Lyard, F.; Lefevre, F.; Letellier, T.; Francis, O. Modelling the global ocean tides: Modern insights from FES2004. Ocean Dyn. 2006, 56, 394-415. [CrossRef]

48. Soffel, M.; Klioner, S.A.; Petit, G.; Wolf, P.; Kopeikin, S.M.; Bretagnon, P.; Brumberg, V.A.; Capitaine, N.; Damour, T.; Fukushima, T.; et al. The IAU 2000 resolutions for astrometry, celestial mechanics, and metrology in the relativistic framework: Explanatory supplement. Astron. J. 2003, 126, 2687-2706. [CrossRef]

49. Kazmierski, K.; Sosnica, K.; Hadas, T. Quality assessment of multi-GNSS orbits and clocks for real-time precise point positioning. GPS Solut. 2017, 22, 11. [CrossRef]

50. Sośnica, K.; Thaller, D.; Dach, R.; Steigenberger, P.; Beutler, G.; Arnold, D.; Jäggi, A. Satellite laser ranging to GPS and GLONASS. J. Geod. 2015, 89, 725-743. [CrossRef]

51. Tan, B.; Yuan, Y.; Wen, M.; Ning, Y.; Liu, X. Initial Results of the Precise Orbit Determination for the New-Generation BeiDou Satellites (BeiDou-3) Based on the iGMAS Network. ISPRS Int. J. Geo-Inf. 2016, 5, 196. [CrossRef]

52. Deng, Z.; Fritsche, M.; Uhlemann, M.; Wickert, J.; Schuh, H. Reprocessing of GFZ multi-GNSS product GBM. In Proceedings of the IGS Workshop, Sydney, Australia, 8-12 February 2016; pp. 8-12. 